\title{
Elucidation of Human Choline Kinase Crystal Structures in Complex with the Products ADP or Phosphocholine
}

\author{
Enrico Malito ${ }^{1}$, Nikolina Sekulic ${ }^{1} \uparrow$, Wei Cun See Too $^{2} \dagger$ \\ Manfred Konrad ${ }^{2}$ and Arnon Lavie ${ }^{1 *}$
}

\author{
${ }^{1}$ Department of Biochemistry \\ and Molecular Genetics \\ University of Illinois at Chicago \\ Chicago, IL 60607, USA \\ ${ }^{2}$ Department of Molecular \\ Genetics, Max Planck Institute \\ for Biophysical Chemistry \\ Göttingen, D-37077, Germany
}

\begin{abstract}
Choline kinase, responsible for the phosphorylation of choline to phosphocholine as the first step of the CDP-choline pathway for the biosynthesis of phosphatidylcholine, has been recognized as a new target for anticancer therapy. Crystal structures of human choline kinase in its apo, ADP and phosphocholine-bound complexes, respectively, reveal the molecular details of the substrate binding sites. ATP binds in a cavity where residues from both the $\mathrm{N}$ and C-terminal lobes contribute to form a cleft, while the choline-binding site constitutes a deep hydrophobic groove in the C-terminal domain with a rim composed of negatively charged residues. Upon binding of choline, the enzyme undergoes conformational changes independently affecting the N-terminal domain and the ATPbinding loop. From this structural analysis and comparison with other kinases, and from mutagenesis data on the homologous Caenorhabditis elegans choline kinase, a model of the ternary ADP.phosphocholine complex was built that reveals the molecular basis for the phosphoryl transfer activity of this enzyme.
\end{abstract}

(C) 2006 Elsevier Ltd. All rights reserved.

Keywords: choline kinase; phosphoryl transfer; crystal structure

\section{Introduction}

Phosphatidylcholine (PtdCho) represents the most abundant class of phospholipids in eukaryotic cells. Together with other phospholipids, such as phosphatidylethanolamine and neutral lipids, it is the major structural component of the membrane bilayer. In addition to constituting $40-60 \%$ of the phospholipid content of eukaryotic cell membranes, ${ }^{1}$ PtdCho has been recognized as an important source of second messenger molecules. ${ }^{2}$ The biosynthesis of phosphatidylcholine is primarily accomplished by the CDP-choline pathway, also called the Kennedy pathway. The first step of the pathway is the phosphorylation of choline to phosphocholine (PChol), catalyzed by choline ki-

$\dagger$ N.S. and W.C.S.T. contributed equally to this work.

Abbreviations used: CK, choline kinase; hCK, human CK; PChol, phosphocholine; PtdCho, phosphatidylcholine; $\mathrm{hCK} \alpha 2$, human choline kinase isoform $\alpha 2$; ePK, eukaryotic protein kinase; APHs, aminoglycoside phosphotransferases.

E-mail address of the corresponding author: lavie@uic.edu nase (CK) (E.C. 2.7.1.32). ${ }^{3}$ The level of PChol, which is both a precursor and a breakdown product of PtdCho, needs to be tightly regulated to maintain cell integrity. Therefore, any changes in CK activity may alter the total content of this component and its ratio to other metabolites that play critical roles in membrane structure and cell signaling processes. Notably, cell-biological and genetic studies have highlighted the interplay between the pathways for PtdCho metabolism and Golgi-dependent secretory processes. $^{4,5}$

Several discoveries have recently revealed the importance of PtdCho to mammalian cell physiology. Alterations of PtdCho metabolism are associated to different key cellular events, such as oncogenic transformation and programmed cell death. ${ }^{6,7}$ Increased CK enzymatic activity, and consequently increased levels of PtdCho, has been detected in ras transformed cells. ${ }^{8}$ Similarly, CK is overexpressed in breast, lung, colon, and prostate tumors, 7,9 and increased levels of PChol have been detected by nuclear magnetic resonance studies of human tumoral tissues. ${ }^{10,11}$ More recently, convincing evidence for the oncogenic potential of choline kinase has been reported. ${ }^{12}$ From these studies, choline kinase is thought to behave as an oncogene 
by itself, and lays downstream of RhoA GTPasedependent signaling processes. Although activation of CK by RhoA is not mediated by a direct proteinprotein interaction, strong evidence that choline kinase may be a new relevant molecule in RhoAinduced oncogenic transformation has recently been provided. $^{12}$

Observations showing a direct link between PtdCho homeostasis and carcinogenesis strongly suggest the potential use of choline kinase as a new marker for malignancy and, accordingly, as a potential target for anticancer therapy. In fact, CK inhibitors showing efficient antitumoral activity have already been generated, ${ }^{13-16}$ and are currently under investigation both in vitro and in vivo. Most significantly, these studies have demonstrated that inhibition of CK activity is reflected in a decrease of PChol and total choline levels, leading to pronounced antiproliferative effects in various human tumor-derived cell lines and in animal models. ${ }^{17,18}$ However, it must be kept in mind that presently available CK inhibitors may also affect other molecules involved in signal transduction pathways and cell cycle regulation.

In mammals, choline kinase exists as at least three isoforms, encoded by two separate genes named $c k$ $\alpha$ and $c k-\beta$. While $c k-\beta$ codes for a single protein $(C K-\beta), c k-\alpha$ undergoes alternative splicing and is thus responsible for the production of two CK isoforms, CK- $\alpha 1$ and $C K-\alpha 2$. Each isoform is present as either dimers (homo- or hetero-) or as tetramers in solution. ${ }^{19}$ To gain insight into the structural and functional features of this family of enzymes, and to facilitate the structure-based design of specific inhibitors of human CKs, we solved the crystal structure of human choline kinase isoform $\alpha 2$ $(\mathrm{hCK} \alpha 2)$ in its apo form and in complex with the reaction products ADP or phosphocholine. These structures allow us to identify for the first time the substrate binding sites of $C K$, to correlate active site residues with results from previous mutational studies, and reveal the conformational changes that occur upon substrate binding. In addition, the structural analysis allowed us to generate a model of the ternary hCK $\alpha 2 \cdot A D P \cdot P C h o l$ complex that reveals the molecular basis for the enzymatic activity of choline kinase.

\section{Results and Discussion}

\section{Overall structure}

The human choline kinase (hCK) isoform $\mathrm{hCK} \alpha 2$ used in this study consists of 457 amino acid residues with a molecular mass of $\sim 52 \mathrm{kDa}$. The protein was overproduced as an N-terminal truncation mutant. Table 1 shows the kinetic parameters for full length and $\Delta 49 \mathrm{~N}-\mathrm{hCK} \alpha 2$ under identical assay conditions, with choline as substrate. The results demonstrate that the truncated construct has very similar $V_{\max }$ and slightly lower $K_{\mathrm{m}}$ for choline
Table 1. Kinetic constants for purified full length and $\Delta 49 \mathrm{~N}-\mathrm{hCK} \alpha 2$

\begin{tabular}{lccc}
\hline & \multirow{2}{c}{$k_{\text {cat }}$} & \multicolumn{2}{c}{$K_{\mathrm{m}}(\mathrm{mM})$} \\
\cline { 3 - 4 } Construct & 83.1 & 0.098 & 0.41 \\
\hline Full length hCK $\alpha 2$ & 71.5 & 0.072 & 0.45 \\
$\Delta 49 \mathrm{~N}-\mathrm{s} C K \alpha 2$ & 18.6 & 1.69 & 0.35 \\
\hline hCK $\alpha 1$ & & &
\end{tabular}

Choline kinase activity was assayed as described in Materials and Methods. The data were analyzed according to Michaelis-Menten equation using the Microcal Origin version 5.0 non-linear curvefitting program.

compared to wild-type protein, indicating that the non-conserved region at the $\mathrm{N}$ terminus of $\mathrm{hCK} \alpha 2$ is not essential for catalysis.

The structure of the human $\Delta 49$-hCK $\alpha 2$.Apoenzyme $\left(\mathrm{hCK}_{\mathrm{Apo}}\right)$ was solved by the molecular replacement method using as search model coordinates from choline kinase A-2 of Caenorhabditis elegans (CKA-2, PDB id 1NW1), ${ }^{20}$ and refined at $2.15 \AA$ resolution (Figure 1 ). Crystals of the complex forms were obtained by soaking native crystals with $10 \mathrm{mM}$ ADP or $20 \mathrm{mM}$ PChol, respectively. Starting from coordinates of the refined $\mathrm{hCK}_{\mathrm{Apo}}$, product-bound structures were solved by the molecular replacement method and refined to $3.1 \AA$ and $2.4 \AA$ resolution for the $\mathrm{CK}$ ADP complex and the CK-PChol complex, respectively. For the dimer that makes up the asymmetric unit, electron density clearly shows the presence of a molecule of ADP in one of the monomers of the $\Delta 49-\mathrm{hCK} \alpha 2 \cdot \mathrm{ADP}$ (designated $\mathrm{hCK}_{\mathrm{ADP}}$ ) complex, and of one PChol molecule in each monomer of the $\Delta 49-\mathrm{hCK} \alpha 2 \cdot \mathrm{PCh}$ (designated $\mathrm{hCK}_{\mathrm{PChol}}$ ) complex. The observation of ADP bound to only one of the two monomers could be due to several factors, such as the rather high $K_{\mathrm{m}}$ of ADP (Table 1) or the environment in the crystal. The refined structures (Table 2) exhibit good stereochemical parameters with no residues in the disallowed regions of the Ramachandran plot.

The structure of hCK $\alpha 2$ reveals the typical eukaryotic protein kinase fold. ${ }^{20}$ Choline kinases and aminoglycoside phosphotransferases (APHs) have been classified as the most representative members of the so-called "atypical kinases" (AKs) family of enzymes. These enzymes clearly share homology with the eukaryotic protein kinases (ePKs) catalytic core but do not conserve all of the usual kinase motifs. ${ }^{21}$ Recently the apo structure of the nematode C. elegans choline kinase (CKA-2), which exhibits $42 \%$ sequence identity with $\mathrm{hCK} \alpha 2$, has been reported. ${ }^{20}$ Comparison of the protein structures reveals a similar folding topology between these two choline kinases. While the mean deviation of position between corresponding $\mathrm{C}^{\alpha}$ atoms encompassing the complete structure is relatively large (rmsd of $3.4 \AA$ between the two apo forms), the individual domains overlay with a smaller rmsd (1.48 $\AA$ and $1.94 \AA$ for the $\mathrm{N}$ and C-terminal 
(a)

(b)
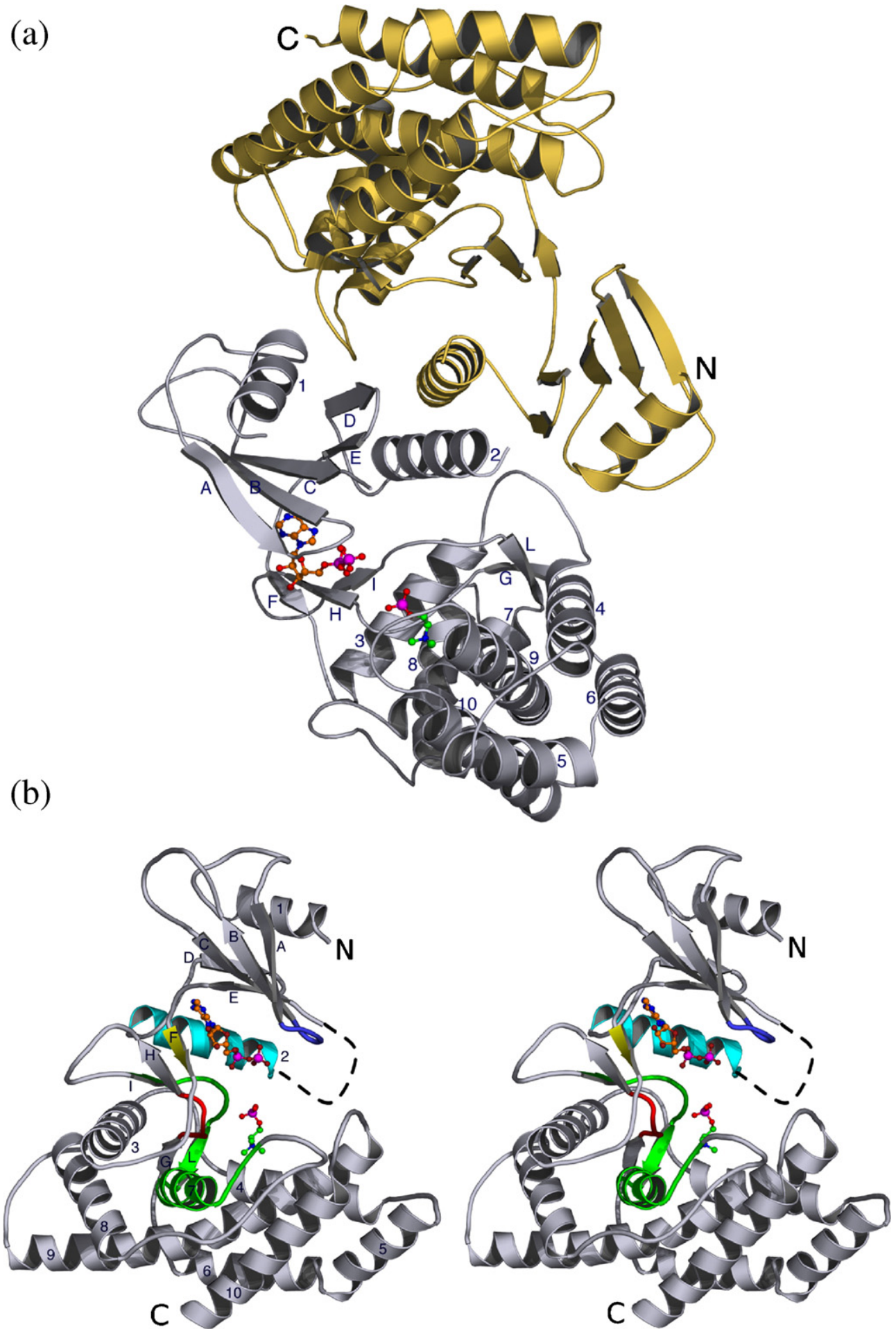

Figure 1. Ribbon diagram of apo hCK $\alpha 2$, and with ADP and PChol molecules concomitantly present as modeled on the basis of the determined $\mathrm{hCK}_{\mathrm{ADP}}$ and $\mathrm{hCK} \mathrm{K}_{\mathrm{PChol}}$ complex structures. (a) $\mathrm{hCK}_{\mathrm{Apo}}$ dimer (gray/yellow ribbon) oriented with the 2-fold non-crystallographic axes perpendicular to the plane of the page. Dimer formation buries $2100 \AA^{2}$, where helix 2 plays a major role. (b) Stereo diagram of a hCK $\alpha 2$ monomer drawn after a vertical rotation of $90^{\circ}$ with respect to the orientation in (a). Key structural elements are colored: the ATP-binding loop in blue, the dimer interface $\alpha$-helix in cyan, the short $\beta$-strand that links the $\mathrm{N}$ and C-terminal domains in yellow, the Brenner's motif in red, and the choline kinase motif in green. In this and the following Figures, ball-and-stick representation of ADP and PChol molecules are shown with their carbon atoms colored in orange and green, respectively. Oxygen, nitrogen and phosphate atoms are shown in red, blue and magenta, respectively. All structure Figures were made with Pymol. [http://www.pymol.org].

domains, respectively). The most significant difference centers at residues 262-281 (hCK $\alpha 2$ numbering). This segment comprises an $\alpha$-helix in $\mathrm{hCK} \alpha 2$
(Figure 1(a) and (b), helix 5) instead of two short $\beta$ strands ( 7 and 8 , CKA-2 numbering), and is not part of any catalytically relevant region. Each monomer 
Table 2. Data collection and refinement statistics

\begin{tabular}{|c|c|c|c|}
\hline & Apo & ADP & P-Chol \\
\hline X-ray source & CHESS-A1 & \multicolumn{2}{|c|}{ APS-SerCAT-ID22 } \\
\hline 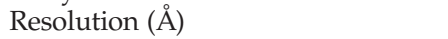 & 2.15 & 3.1 & 2.4 \\
\hline Space group & $P 2_{1} 2_{1} 2_{1}$ & $P 2_{1} 2_{1} 2_{1}$ & $P 2_{1} 2_{1} 2_{1}$ \\
\hline Cell $(\AA)$ & $56.2,122.8,132.1$ & $52.3,127.1,158.7$ & $52.5,128.3,172.2$ \\
\hline$R_{\mathrm{sym}}^{\mathrm{a}, \mathrm{b}}$ & $11.0(62.5)$ & $14.7(61.2)$ & $11.4(57.4)$ \\
\hline Completeness $(\%)^{\mathrm{a}}$ & $99.9(100)$ & $99.3(93.9)$ & $99.8(99.1)$ \\
\hline$I / \sigma(I)^{\mathrm{a}}$ & $20.38(5.76)$ & $16.2(2.3)$ & $13.9(3.2)$ \\
\hline Total reflections ${ }^{\mathrm{a}}$ & $906,892(113,984)$ & $190,216(12,100)$ & $375,565(31,936)$ \\
\hline Unique reflections $^{\mathrm{a}}$ & $50,560(6366)$ & $19,759(1806)$ & $46,369(5201)$ \\
\hline Redundancy ${ }^{\mathrm{a}}$ & $17.9(17.9)$ & $9.6(6.7)$ & $8.1(6.1)$ \\
\hline$R$-factor $\left(R_{\text {free }}\right)^{\mathrm{c}}$ & $19.8(25.6)$ & $26.3(32.8)$ & $21.4(25.8)$ \\
\hline No. of non-hydrogen protein atoms & 5686 & 4627 & 5576 \\
\hline No. of water molecules & 417 & 26 & 109 \\
\hline No. of cofactors atoms & - & 27 & 22 \\
\hline rmsd bond length $(\AA)^{\mathrm{d}}$ & 0.014 & 0.010 & 0.009 \\
\hline rmsd bond angle $\left({ }^{\circ}\right)^{\mathrm{d}}$ & 1.371 & 1.369 & 1.225 \\
\hline Average $B$ factor $\left(\AA^{2}\right)$ & 35.99 & 51.31 & 35.66 \\
\hline \multicolumn{4}{|l|}{ Ramachandran plot ${ }^{e}, \%$} \\
\hline Most allowed & 93.2 & 83.4 & 92.9 \\
\hline Additional allowed & 6.7 & 14.8 & 7.0 \\
\hline Generously allowed & 0.2 & 1.8 & 0.2 \\
\hline Disallowed & 0.0 & 0.0 & 0.0 \\
\hline \multicolumn{4}{|c|}{$\begin{array}{l}\text { a Data for the highest resolution shell are given in parenthesis. } \\
\text { b } R_{\text {sym }}=\sum_{\mathrm{h}} \sum_{\mathrm{i}}\left|I_{\mathrm{i}}(h k l)-<I(h k l)>\right| / \sum_{\mathrm{h}} \sum_{\mathrm{i}} I(h k l) \text {. } \\
\text { c } R_{\text {factor }}=\sum|| F_{\text {obs }}|-| F_{\text {calc }} \| / \sum\left|F_{\text {obs }}\right| R_{\text {free }} \text { is the } R_{\text {factor }} \text { value for } 5 \% \text { of the reflections excluded from the refinement. } \\
\text { d Root mean square deviations (rmsd) from ideal values calculated with Refmac. }{ }^{39} \\
\text { e Figures from Procheck. }{ }^{44}\end{array}$} \\
\hline
\end{tabular}

of the asymmetric unit dimer is composed of two domains connected by a short $\beta$-strand (residues 211-214) (Figure 1(a) and (b), strand F). Note that in this, and other Figures presented here, we modeled the presence of both substrates, so as to better orient the two binding sites. However, our structures of hCK $\alpha 2$ contain either no substrate, only PChol, or only ADP.

The N-terminal 30 amino acid residues (residues 49-80) of our construct are not visible in the electron density maps of all three structures, indicating that they are disordered in the crystals. The smaller domain of the two-domain enzyme, the N-terminal domain, is composed of a five-stranded antiparallel $\beta$-sheet and a single $\alpha$-helix (Figure $1(\mathrm{a})$ and (b), helix 1 and $\beta$-strands $A-E)$. Inserted between the third (C) and the fourth (D) strands of this $\beta$-sheet is an $\alpha$-helix that forms the interface stabilizing the protein as a dimer (Figure 1(a) and (b), helix 2). Amino acids belonging to the region connecting the third $\beta$-strand with the interface helix are not visible in electron density maps of all three structures (residues 152-176, Figure 1(b), black-broken line). Interestingly, this sequence segment represents the only difference between human choline kinase $\alpha 1$ and $\alpha 2$, in which an additional 18 amino acid residue insertion is incorporated in $\alpha 2$. Although further studies are required to completely elucidate the function of this 18 amino acid residue insertion, we observed that when present (i.e. in hCK $\alpha 2$ ) the insertion lowers the $K_{\mathrm{m}}$ for choline to $0.10 \mathrm{mM}$, in comparison to the much higher value of $1.69 \mathrm{mM}$ for $\mathrm{hCK} \alpha 1$. How this dramatic lowering of choline $K_{\mathrm{m}}$ is achieved cannot be conclusively answered by our structures. However, a structural analysis of this region reveals that it may be important for facilitating the conformational changes that take place upon substrate binding.

The C-terminal domain is primarily helical, and contains many of the conserved and functionally important residues. The loop comprising residues 302-311 (Figure 1(b), red) is the so-called Brenner's motif, $^{22}$ whereas the region including residues $326-$ 349 (Figure 1(b), green) is the choline kinase motif. Several residues belonging to these motifs are highly conserved among CKs, ePKs and APHs, and have critical catalytic functions (Figure 2).

\section{ATP binding site}

The structure of the $\mathrm{hCK}_{\mathrm{ADP}}$ complex reveals how the nucleotide is bound in a cleft between the two domains of the enzyme. Residues from both the $\mathrm{N}$ and C-terminal lobes contribute to the formation of a large pocket in which the nucleotide (ADP or ATP) binds (Figure 1(b)).

The adenine ring makes $\mathrm{H}$-bond interactions between the N1 and N6 atoms and the polypeptide backbone carbonyl oxygen of Ile209 and Gln207 (Figure 3(a) and (b)). The N6 atom is also within H-bond distance from the side-chain OE2 of Glu206. These interactions explain the specificity of $\mathrm{hCK} \alpha 2$ for ATP, and are consistent with the observation that no enzymatic activity was detected when non-adenine containing NTPs were substituted for ATP in the enzyme assay (data not shown). In addition, two conserved hydrophobic residues (Leu144 and Leu313) are positioned on both sides of the adenine 
$\triangle 49-\mathrm{hCK \alpha}-2$

hCK $\alpha-2 \quad 1$ MKTKFCTGGE AEPSPLGLLL SCGSGSAAPA PGVGQQRDAA SDLESKQLGG QQPPLALPPP PPLPLPLPLP QPPPPQPPAD 80 hCK $\alpha-1$ MKTKFCTGGE AEPSPLGLLL SCGSGSAPA PGVGQQRDAA SDLESKQLGG QQPPLALPPP PPLPLPLPLP QPPPPQPPAD 80 hCK $\beta-2 \quad 1$----------- ----------- -----MAAEA TAVAGSGAVG GCLAKDGLQQ SKCPDTTP-- ----------- ------KRRRA 38 CCKA-2 11 --------- -------MS SRKVSRAHYD EDELASAANM SLVAEGHFRG MKELLSTM-- ---------- -----DLDTD 45 mCK $\alpha-1 \quad 1 \quad$ MKTKFCTGGE AEPSPLGLLL SCG-GNAAPT PGVGQQRDAA GELESKQLGG RTQPLALPPP PPPPLPLP-- -PPPSPPLAD 76

(1)

first visible residue

$\mathrm{hCK} \alpha-2$

hCK $\alpha-1$

hсK $\beta-2$

CCKA-2

$\mathrm{mCK} \alpha-1$

$\mathrm{mCK} \beta$

APH

CAPK

$\mathrm{hCK} \alpha-2$

hCK $\alpha-1$

hCK $\beta-2$

CCKA-2

mCK $\alpha-1$

$\operatorname{mCK} \beta$

APH

CAPK

$\mathrm{hCK} \alpha-2$

hCK $\alpha-2$

hск $\beta-2$

CCKA-2

$\mathrm{mCK} \alpha-1$

$\operatorname{mCK} \beta$

APH

CAPK
ATP-binding loop

$$
\text { a c ca a }
$$

a a

SNMLFOCSLP DTTATLGDEP RKVLLRLYGA ILOVRSCNKE 160 SNMLFOCSLP DTTATLGDEP RKVLLRLYGA ILOV------ 154 SNLLFRCSLP DHLPSVGEEP REVLLRLYGA ILQG------ 112 SNMFLCRLS EVYPPIRNEP NKVLLRVYFN PETE------- 119 NMLFOCSLP DSIASVGDEP RKVLLRLYGA ILKMRSCNKE 156 SNLLFRCSLP NHVPSVGGEP REVLLRLYGA ILQG------ 112

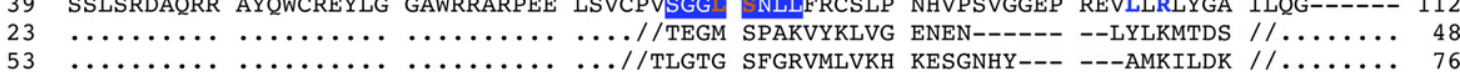
SSLSRDAERR AYQWCREYLG GAWRRVQPEE LRVYPV 77 EOPEPRTRRR AHMLCARFLG GAWKTVPLEH LRISRIKGCH GAWRGLREDQ FHISVIRGG 9 SSLSRDAQRR AYQWCREYLG GAWRRARPEE LSVCPVSGG

\section{-0-0-0 dimer interface a a a a

$$
\text { aa a a a }
$$

161 GSEQAOKENE FQGAEAMVLE SVMFAILAER SLGPKLYGIF PQGRLEOFIP SRRLDTEELG LPDISAEIAE KMATFHGMKM 240 113 -------- ---VDSLVLE SVMFAILAER SLGPQLYGVF PEGRLEOYIP SRPLKTQELR EPVLSAAIAT KMAQFHGMEM 179 120 -------- ----SHLVAE SVIFTLLSER HLGPKLYGIF SGGRLEEYIP SRPLSCHEIS LAHMSTKIAK RVAKVHQLEV 185 157 GSEQAQNENE FOGAEAMVLE SVMFAILAER SLGPKLYGIF PQGRLEQFIP SRRLDTEELR LPDISAEIAE KMATFHGMKM 236 113 --------- ---VDSLVLE SVMFAILAER SLGPQLYGVF PEGRLEQYLP SRPLKTQELR DPVLSGAIAT RMARFHGMEM 179

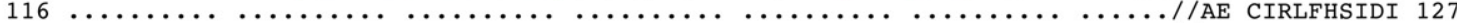

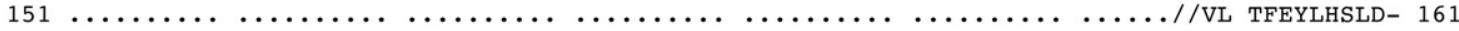

Brenner's motif 241 PFNKEPKWLF GTMEKYLKEV LR-IKFTEES RIKKLH---K LLSYNLPLEL ENLRSLLEST PSPVVFCHN C EG ILLLE 316 223 PFNKEPKWLF GTMEKYLKEV LR-IKFTEES RIKKLH---K LLSYNLPLEL ENLRSLLEST PSPVVFCHN C EG ILLLE 298 180 PFTKEPHWLF GTMERYLKQI QD-LPPTG-- -LPEMN---L LEMYSLKDEM GNLRKLLEST PSPVVFCHN I EG ILLLS 252 186 PIWKEPDYLC EALQRWLKQL TGTVDAEHRF DLPEECGVSS VNCLDLAREL EFLRAHISLS KSPVTFCHN L EG ILLPK 265 237 PFNKEPKWLF GTMEKYLNOV LR-LKFSREA RVOOLH---K ILSYNLPLEL ENLRSLLOYT RSPVVFCHN C EG ILLLE 312 180 PFTKEPRWLF GTMERYLKQI QD-LPSTS-- -LPQMN---L VEMYSLKDEM NSLRKLLDDT PSPVVFCHN I EG ILLLS 252

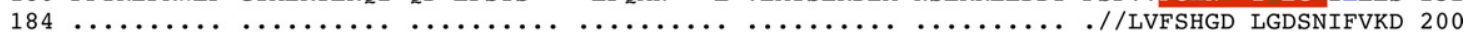

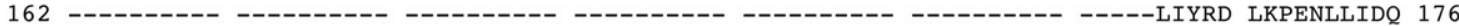

\section{choline kinase motif}

$$
\text { a h }
$$

hCK $\alpha-2 \quad 317$ GRE----- - - hCK $\alpha-1299$ GRE------ ---_--- ----NSEKO KLMLIDFEYS SYNYRGFDIG NHFC WMYDY SYEKYPFFRA NIRKYPTKKO 356 hCK $\beta-2 \quad 253$ EPE------ -- - 2 CCKA-2 266 ASSGNIRMPS LSDETQALGN SLSAFNPADP RLVLIDFEYA SYNYRAFDFA NHFIEWTIDY DIDEAPFYKI QTENFPENDQ 345 mCK $\alpha-1 \quad 313$ GQE------ ------- ----NSERR KLMLIDFEYS SYNYRGFDIG NHFC WMYDY TYEKYPFFRA NIQKYPSRKQ 370 mCK $\beta 253$ EPD------ -------- ----SDD-- NLMLVDFEYS SYNYRGFDIG NHFC WVYDY TYEEWPFYKA RPTDYPTREQ 308

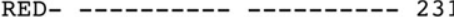

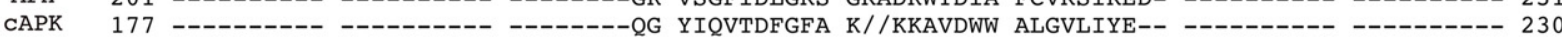

hCK $\alpha-2375$ OLHFISSYLP AFONDFENLS TEEKSIIKEE MLLEVNRFAL ASHFLWGOWS IVOAKISSIE FGYMDYAOAR FDAYFHOKRK 454 hCK $\alpha-1 \quad 357$ QLHFISSYLP AFQNDFENLS TEEKSIIKEE MLLEVNRFAL ASHFLWGQWS IVQAKISSIE FGYMDYAQAR FDAYFHQKRK 436 hCK $\beta-2 \quad 309$ QLHFIRHYLA EAKKG-ETLS QEEQRKLEED LLVEVSRYAL ASHFFWGLWS ILQASMSTIE FGYLDYAQSR FQFYFQQKGQ 387 CCKA-2 346 MLEFFLNYLR EQGNT----R ENELYKKSED LVQETLPFVP VSHFFWGVWG LLQVELSPVG FGFADYGRDR LSLYFKHKQL 421

mCK $\alpha-1371$ QLHFISSYLT TFONDFESLS SEEQFATKED MLLEVNRFAL ASHFLWGLWS IVOAKISSIE FGYMEYAOAR FEAYFDOKRK 450 mCK 309 QLHFIRHYLA EVQKG-EILS EEEQKKREEE LLLEISRYSL ASHFFWGLWS TLQASMSTIE FGYLEYAQSR FQFYFQQKGQ 387

$\begin{array}{crll}\text { hCK } \alpha-2 & 455 & \text { LGV----- } & 457 \\ \text { hCK } \alpha-1 & 437 & \text { LGV----- } & 439 \\ \text { hCK } \beta-2 & 388 & \text { LTSVHSSS } & 395 \\ \text { CCKA-2 } & 422 & \text { LKNLASHQ } & 429 \\ \text { mCK } \alpha-1 & 451 & \text { LGV----- } & 453 \\ \text { mCK } \beta & 388 & \text { LTSSPSS- } & 394\end{array}$

Figure 2. Sequence alignment of choline kinases, APH(3')-IIIa and cAPK obtained with the ClustalW algorithm. Key structural elements are shaded with different colors according to Figure 1(b). Residue that directly interact with ATP are marked by an a, those with choline by a c, and the hydrophobic residues that surround the choline by an h. Residues revealed by mutagenesis experiments to play a structural role are labeled with an s. hCK denotes human choline kinases, $\mathrm{mCK}$ from mouse, and $\mathrm{cCK}$ from C. elegans. The sequence alignment for APH(3')-IIIa (APH) and cAPK is shown only for catalytically important residues. Sequence breaks for the latter two are denoted with / / and sequence not included in this alignment with period marks (..). Gaps in a sequence are marked with --. The region marked with black broken line represents the 18 amino acid residue insertion that distinguishes $\mathrm{hCK} \alpha-2$ from $\mathrm{hCK} \alpha-1$ and that is not visible in all our crystal structures. The first residue in our $\Delta 49-\mathrm{hCK} \alpha-2$ construct is indicated by an arrow, and so is the first visible residue in our crystal structures. 
ring, contributing therefore to the right positioning and binding of the nucleotide. The ribose component interacts with the protein via $\mathrm{H}$-bonds between the polypeptide backbone carbonyl oxygen of Ser211 and the O2' of the sugar, and between the backbone amide of Arg213 (modeled as alanine) and the O3' of the sugar. Correct positioning of the ribose is also assured by the conserved Leu124 (see Table 3 for a list of ADP-enzyme interactions).

The interactions of the nucleotide phosphate groups involve the side-chains of conserved active site residues. The $\alpha$-phosphate makes polar interactions with the side-chain NH1 atom of Arg146, positioned on the N-terminal five-stranded antiparallel $\beta$-sheet of hCK $\alpha 2$ and conserved among all $\mathrm{CKs}$ and ePKs. Its side-chain projects toward the ATP binding pocket, and its position is consistent with the invariant lysine in ePKs that directly participates in nucleotide binding. ${ }^{23}$ The $\alpha$-phosphate also makes $\mathrm{H}$-bond interactions with Asp330, a catalytically critical residue residing in the choline kinase motif. This residue is conserved among all CKs, ePKs and APHs, and when mutated it completely abolishes CK activity. ${ }^{24}$ In $\mathrm{APH}\left(3^{\prime}\right)$-IIIa this Asp is essential for the coordination of two $\mathrm{Mg}^{2+}$ that bind to ATP. The electron density map of our hCK $\mathrm{ADP}$ crystal structure does not show any peak interpretable as metal ion in the active site.

The $\beta$-phosphate forms $\mathrm{H}$-bond interactions with two protein atoms. Both $\mathrm{O} 1 \mathrm{~B}$ and $\mathrm{O} 2 \mathrm{~B}$ atoms interact with the atom ND2 of Asn122: this residue is also highly conserved among CKs and ePKs. In addition, the $\mathrm{O} 3 \mathrm{~B}$ atom of the $\beta$-phosphate forms $\mathrm{H}$ bond interactions with both NE and NH2 of Arg117. This last residue shows different conformations between the three crystal structures: in $\mathrm{hCK}_{\mathrm{Apo}}$ Arg117 points towards the empty active site, positioned where we observe the ADP molecule in $\mathrm{hCK}_{\mathrm{ADP}}$; in $\mathrm{hCK}_{\mathrm{ADP}}$ the Arg117 side-chain moves out so to accommodate the ADP molecule and make interactions with its $\beta$-phosphate; in $\mathrm{hCK}_{\mathrm{PChol}}$ Arg117 points in the opposite direction to the active site, towards the solvent accessible exterior of the protein, making no interactions with neighboring residues. Both Arg117 and Asn122 belong to the loop connecting the first and second strands of the $N$-terminal $\beta$-sheet, earlier defined as the ATP binding loop ${ }^{20}$ (residues 116-124). This loop is the equivalent of the $\mathrm{P}$ loop in protein kinases, ${ }^{25}$ and from comparison of the apo and PChol-bound crystal structures, we observe its shift from an open to a closed conformation upon choline-binding (see below).

\section{Choline-binding site}

Choline is the best substrate for hCK $\alpha 2$ with a $K_{\mathrm{m}}$ of $0.07 \mathrm{mM}$ and a $k_{\text {cat }}$ of $71.5 \mathrm{~s}^{-1}$ (Table 1). We first performed extensive co-crystallization and soaking experiments with choline. However, both soaked crystals and those obtained by co-crystallization did not contain a bound substrate molecule as inferred from the inspection of electron density maps. We next performed soaking experiments with PChol and were able to solve the crystal structure of the complex hCK $\mathrm{PChol}$.

The electron density map of $\mathrm{hCK}_{\mathrm{PChol}}$, calculated at 2.4 $\AA$ resolution, reveals a strong peak close to the position of the $\beta$-phosphate of ADP as seen in $\mathrm{hCK}_{\mathrm{ADP}}$ (Figure $4(\mathrm{a})$ ). Residues belonging to the Brenner's motif (302-311) and the choline kinase motif (326-349) on the C-terminal domain participate in the binding of the choline moiety. The phosphate $\mathrm{O} 3$ atom of PChol is positioned within $\mathrm{H}$-bond distance from the side-chain atoms of several conserved active site residues: NE2 of Gln308, OD2 of Asp306, and ND2 of Asn311. These residues belong to the Brenner's motif and except for Gln308, that is conserved only among $\mathrm{CKs}$, are absolutely conserved among all ePKs and APHs. Asp306 plays a critical role in catalysis, as inferred from mutagenesis data and from previous studies on the corresponding residues in ePKs and $\mathrm{APH}\left(3^{\prime}\right)-\mathrm{III} \mathrm{a}^{26,27}$ The phosphate $\mathrm{O} 2$ atom of PChol forms an H-bond with the backbone amide of Leu120. This residue is conserved among all CKs and belongs to the ATP binding loop, as well as Ser121 that makes one H-bond interaction between its OG atom and the phosphate $\mathrm{O} 4$ atom of PChol (see Table 3 for a list of PChol-enzyme interactions).

An extensive network of polar interactions characterizes the residues involved in the cholinebinding site (Figure 4(a) and (b)). Asp306 makes $\mathrm{H}$-bond interactions with two water molecules, interacting with the neighboring Asp330 on one side, and with Asn345 and Glu349 on the opposite side. Both Asn345 and Glu349 are conserved among all CKs, and participate in $\mathrm{H}$-bond interactions with residues at the base of the choline-binding site. Mutagenesis of Glu349 to Ala results in loss of enzyme stability, and this residue seems to have both a catalytic and a structural role. ${ }^{24}$ Asp330 interacts via H-bond with the conserved His304 residue that has a structural role in the active site, as suggested by its mutation to Ala that results in loss of stability. ${ }^{24}$ Emanating from His304 is an additional network of $\mathrm{H}$-bond interactions that involve two other conserved and important residues: His236, present in all CKs, ePKs and APHs, and Asp342, found in all CKs and APHs. Mutation to Ala of this last Asp residue has recently been shown to be responsible for activity inhibition and disruption of the homo-dimer complex in mouse CK- $\alpha 1{ }^{28}$

The architecture of the choline-binding site can be described as a deep hydrophobic groove with a rim composed of negatively charged residues (Figure 5). Thus, both hydrophobic and electrostatic forces are responsible for the interaction between hCK $\alpha 2$ and choline. ${ }^{29}$ The conserved patch of negatively charged residues (Glu215, 217, 218, 309, 349, 357, 434, and Asp353) at the outer boundary of the choline-binding site (Figure 5(b)) can function to direct the choline molecule into the active site. This phenomenon of electrostatic steering has been described previously as a mechanism 
(a)

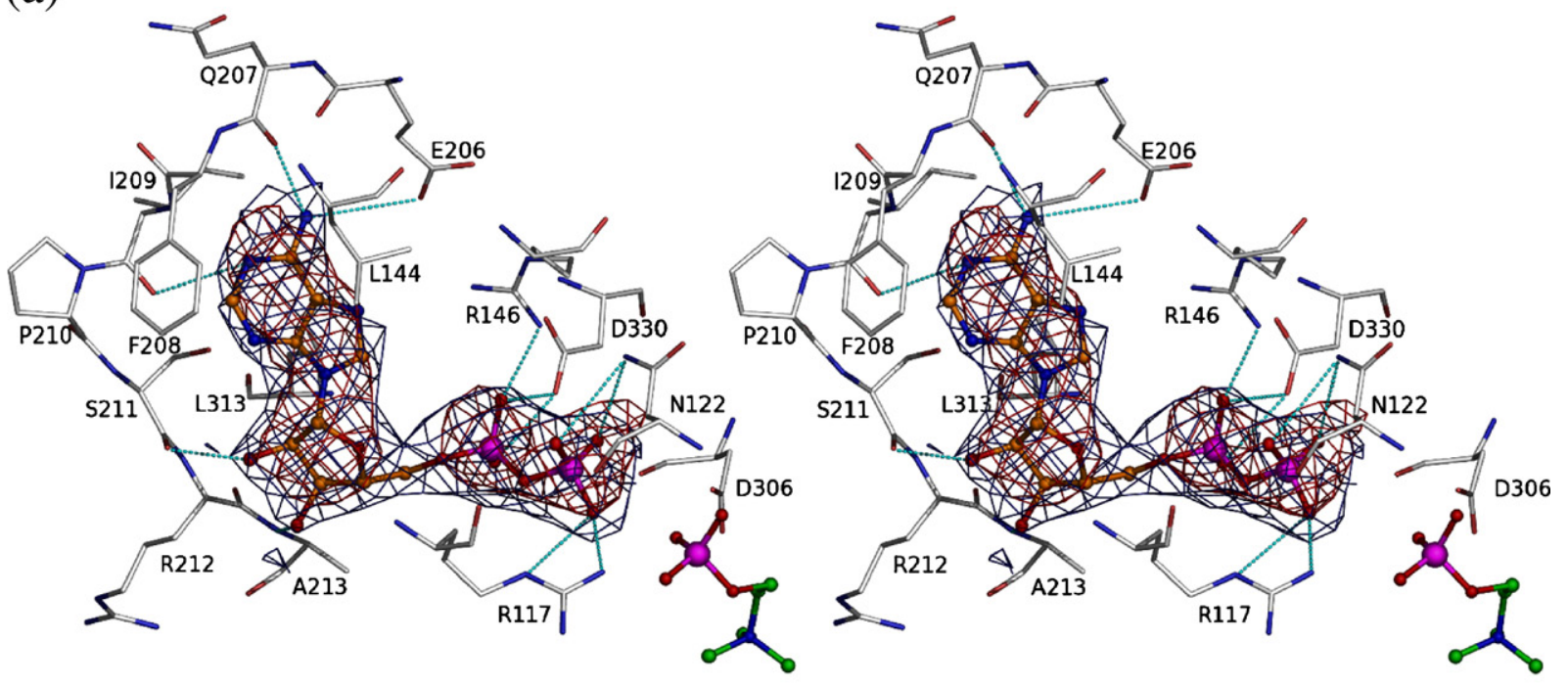

(b)

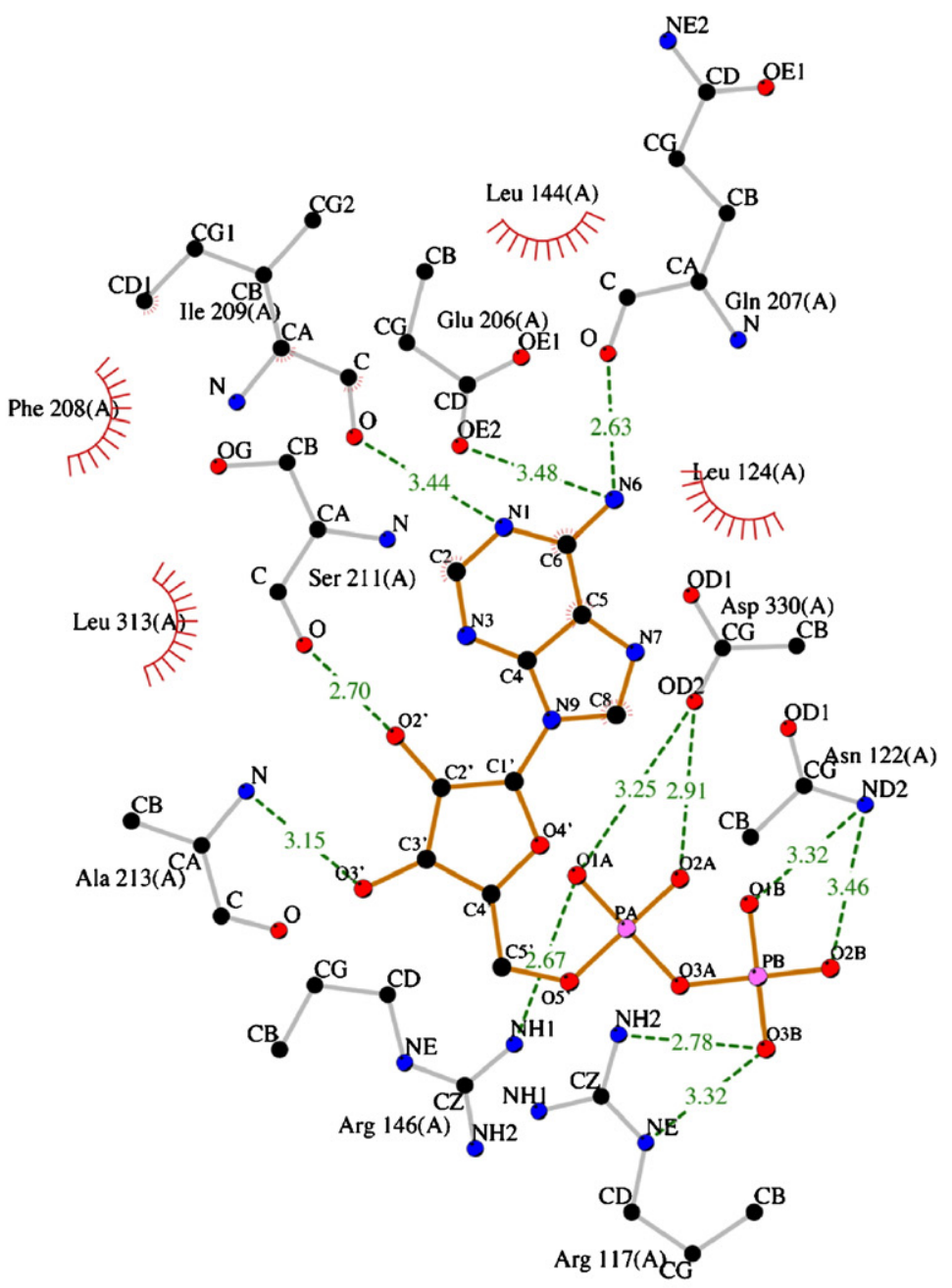

Key

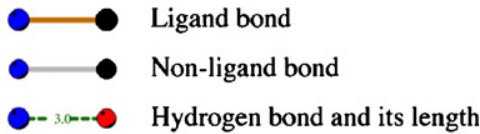

His 53 Non-ligand residues involved in hydrophobic

- Corresponding atoms involved in hydrophobic contact(s)

Figure 3 (legend on opposite page) 
Table 3. Enzyme-products interactions

\begin{tabular}{|c|c|c|}
\hline Protein residues and atoms & ADP & Distances $(\AA)$ \\
\hline \multicolumn{3}{|l|}{ Polar interactions } \\
\hline Arg117 NH2 ${ }^{\mathrm{a}}$ & O3B & 2.78 \\
\hline Arg117 NE & O3B & 3.32 \\
\hline Asn122 ND2 & $\mathrm{O} 4 \mathrm{~B}$ & 3.32 \\
\hline Asn122 ND2 & $\mathrm{O} 2 \mathrm{~B}$ & 3.46 \\
\hline Arg146 NH1 & O1A & 2.67 \\
\hline Glu206 OE2 & N6 & 3.48 \\
\hline Gln207 O & N6 & 2.63 \\
\hline Ile209 O & N1 & 3.44 \\
\hline Ser211 O & $\mathrm{O} 2^{\prime}$ & 2.70 \\
\hline $\operatorname{Arg}($ Ala $) 213 \mathrm{~N}^{\mathrm{b}}$ & $\mathrm{O}^{\prime}$ & 3.15 \\
\hline Asp330 OD2 & O1A & 3.25 \\
\hline Asp330 OD2 & $\mathrm{O} 2 \mathrm{~A}$ & 2.91 \\
\hline \multicolumn{3}{|l|}{ Hydrophobic interactions } \\
\hline Leu124 & Ribose & $\sim 3.5$ \\
\hline Leu144 & Adenine base & $\sim 4$ \\
\hline Leu313 & Adenine base & $\sim 4$ \\
\hline Protein residues and atoms & PChol & Distances $(\AA)$ \\
\hline \multicolumn{3}{|l|}{ Polar interactions } \\
\hline Leu120 N & $\mathrm{O} 2$ & 2.84 \\
\hline Ser121 OG & $\mathrm{O} 4$ & 2.69 \\
\hline Asp306 OD2 & $\mathrm{O} 3$ & 2.28 \\
\hline Gln308 NE2 & $\mathrm{O} 3$ & 3.01 \\
\hline Asn311 ND2 & $\mathrm{O} 3$ & 3.52 \\
\hline \multicolumn{3}{|l|}{ Hydrophobic interactions } \\
\hline Tyr333 & $\mathrm{N}^{+}\left(\mathrm{CH}_{3}\right)_{3}$ & $\sim 5$ \\
\hline Tyr354 & $\mathrm{N}^{+}\left(\mathrm{CH}_{3}\right)_{3}$ & $\sim 4.5$ \\
\hline Trp420 & $\mathrm{N}^{+}\left(\mathrm{CH}_{3}\right)_{3}$ & $\sim 5$ \\
\hline Trp423 & $\mathrm{N}^{+}\left(\mathrm{CH}_{3}\right)_{3}$ & $\sim 4.5$ \\
\hline Tyr440 & $\mathrm{N}^{+}\left(\mathrm{CH}_{3}\right)_{3}$ & $\sim 5$ \\
\hline \multicolumn{3}{|c|}{$\begin{array}{l}\text { a Atomic numbering for the products is shown accordingly } \\
\text { with Ligplot drawings for ADP (Figure 3(b)) and PChol (Figure } \\
\text { 4(b)). } \\
\text { b Arg2 } 213 \text { was modeled as an alanine due to lacking side-chain } \\
\text { electron density. }\end{array}$} \\
\hline
\end{tabular}

to influence the catalytic rate. ${ }^{30}$ While the outer surface of the choline-binding site is dense with negatively charged residues, the base of the pocket that defines the direct choline-binding site is constructed of conserved aromatic residues (Tyr333, 354, 440, and Trp420, 423; see Figure 5 (c)). Once choline is positioned in the active site, its positively charged quaternary amine is stabilized by interactions with the rings of the aromatic residues. Mutagenesis data show that among the hydrophobic conserved residues Trp420 plays a critical role in rate enhancement. In addition, guanidinium hydrochloride-induced denaturation data suggest its involvement in maintaining the overall stability of the enzyme. ${ }^{24}$

\section{Conformational changes and catalysis}

To delineate the conformational changes occurring during catalysis, we compared the two productbound structures with $\mathrm{hCK}_{\mathrm{Apo}}$. Both complexes where superposed on $\mathrm{hCK}_{\mathrm{Apo}}$ using the $\mathrm{C}^{\alpha}$ atoms of residues 90-209 (N-terminal domain), and the $\mathrm{C}^{\alpha}$ atoms of residues 212-457 (C-terminal domain) independently (Figure 6). We could not detect significant conformational changes between $\mathrm{hCK}_{\mathrm{Apo}}$ and $\mathrm{hCK}_{\mathrm{ADP}}$. This could partly be due to the relatively low resolution of the $\mathrm{hCK}_{\mathrm{ADP}}$ structure $(3.1 \AA)$. In contrast, PChol binding gives rise to a significant conformational change that manifests itself both globally, as change in the relative orientation of the N-terminal domain (Figure 6(a)), and locally, as change in the position of the ATP binding loop (Figure 6(b)).

Superposition of $\mathrm{hCK}_{\mathrm{ADP}}$ and $\mathrm{hC} \mathrm{K}_{\mathrm{PChol}}$ on the $\mathrm{hCK}_{\mathrm{Apo}}$ reveals that upon PChol binding the $\mathrm{N}$ terminal domain of $\mathrm{hCK}_{\mathrm{PChol}}$ rotates relative to the C-terminal domain by about 16 degrees. This movement is corroborated by analyzing all three structures using the automated methods implemented in DynDom. ${ }^{31}$ The domain rotation results in a movement of the ATP binding loop by about $10 \AA$ (Figure 6(a)). Pivot points between the two domains can be localized in the zone of the interface, specifically around three segments that include amino acid residues 176-179, 195-196 and 211-214. The last two segments form a double hinge just at the linker between the two domains, while the segment $176-179$ is positioned at the end of the 18 amino acid residues insertion that distinguishes $\mathrm{hCK} \alpha 2$ from $\mathrm{hCK} \alpha 1$. As pointed out before, this segment is not visible in the electron density maps of all three structures. Together with the observation that its presence influences the catalytic activity of $\mathrm{hCK} \alpha 2$ (Table 1 ), this segment most likely plays a critical role in the protein domains rearrangements and the associated catalytic function.

Superposition only of the individual N-terminal domains of the three structures reveals that the ATP binding loop is subjected to a local conformational change independently from the above-mentioned domain rotation. Upon PChol binding, the loop undergoes a shift covering about $7 \AA$, from an open conformation (as observed in $\mathrm{hCK}_{\mathrm{Apo}}$ and $\mathrm{hCK}_{\mathrm{ADP}}$ ) to a closed conformation (Figure 6(b)). In contrast, superposition of the C-terminal domains of all three structures reveals that it is not involved in any significant conformational movement upon ligand binding (Figure 6(c)).

Figure 3. The ATP binding site. (a) Stereo view representation of the ATP-binding site. $2 F_{\mathrm{o}}-F_{\mathrm{c}}$ simulated annealing omit map (red) and sigma-a weighted $2 F_{\mathrm{o}}-F_{\mathrm{c}}$ map (blue) both contoured at $1 \sigma$ are shown around ADP. The relative position of PChol is shown for orientation purposes. The protein carbon, oxygen, nitrogen and phosphate atoms are shown in grey, red, blue and magenta, respectively. H-bonds are shown as cyan broken lines. (b) Ligplot ${ }^{45}$ drawing $^{2}$ showing the interactions of ADP with hCK 2 2. Broken lines indicate all potential H-bonds. "Radiating" spheres indicate hydrophobic contacts between carbon atoms of the nucleotide and the neighboring residues. Ligand-bonds, carbon, oxygen, nitrogen and phosphorous atoms are colored orange, black, red, blue and purple, respectively. Note that we could not observe side-chain density for Arg213 so this residue was modeled as an alanine. 

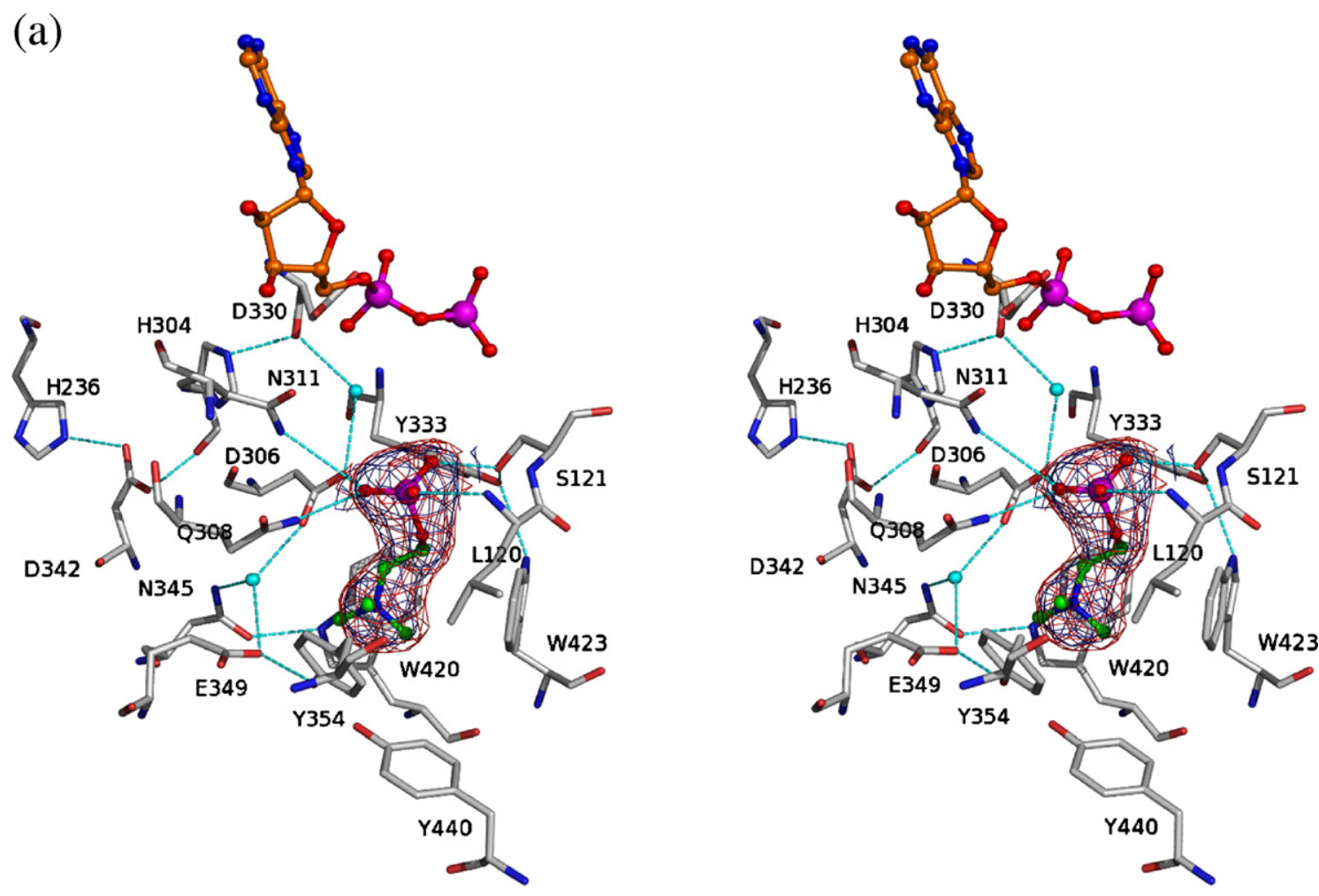

(b)
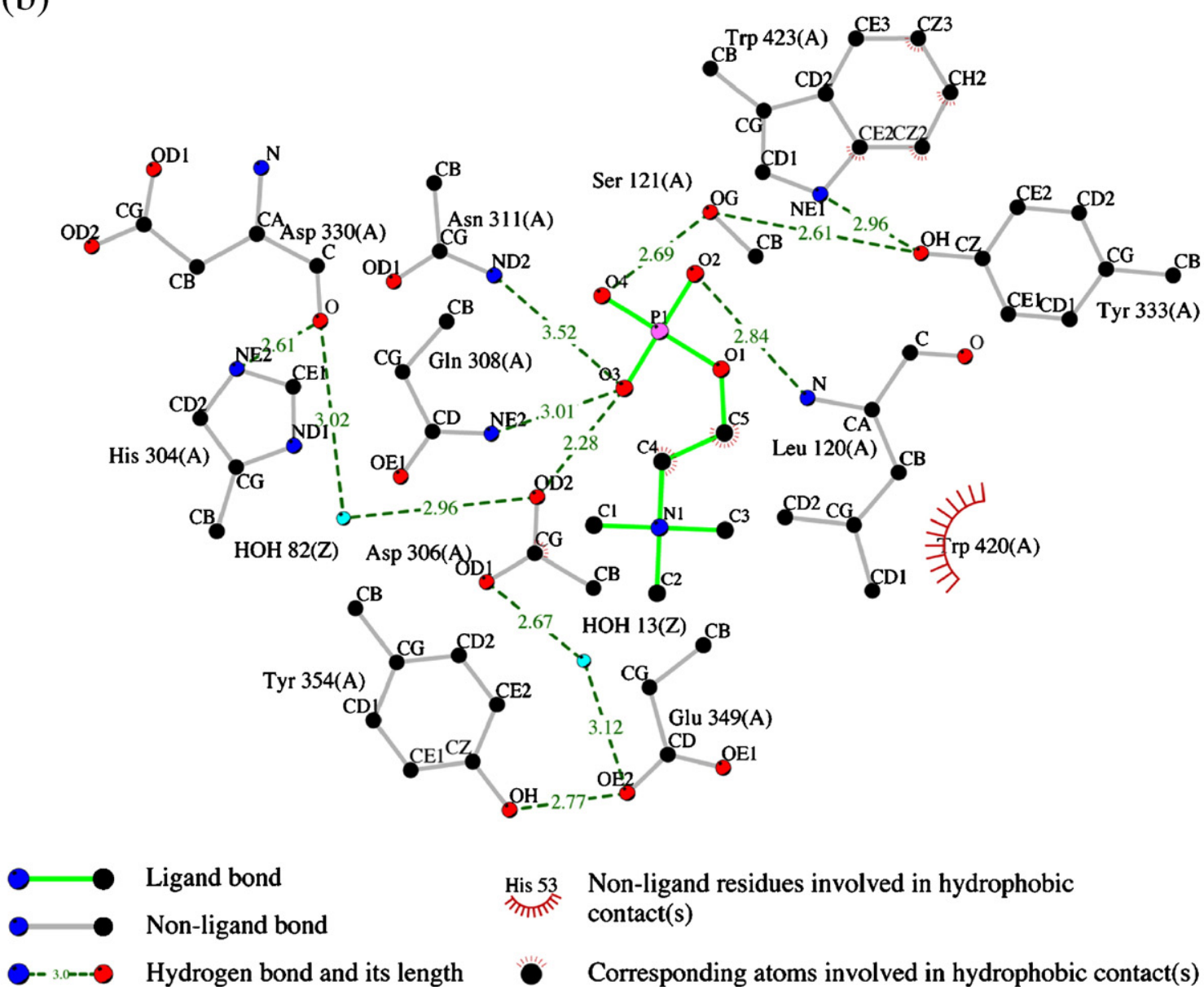
His 53 Non-ligand residues involved in hydrophobic गाm $\operatorname{contact}(\mathrm{s})$

Figure 4 (legend on opposite page) 
(a)

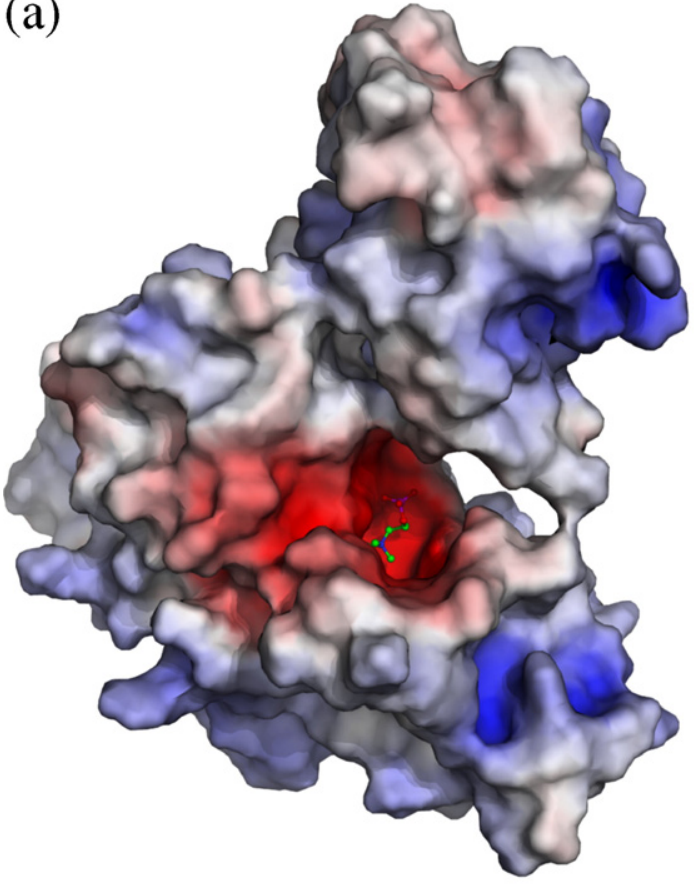

(b)

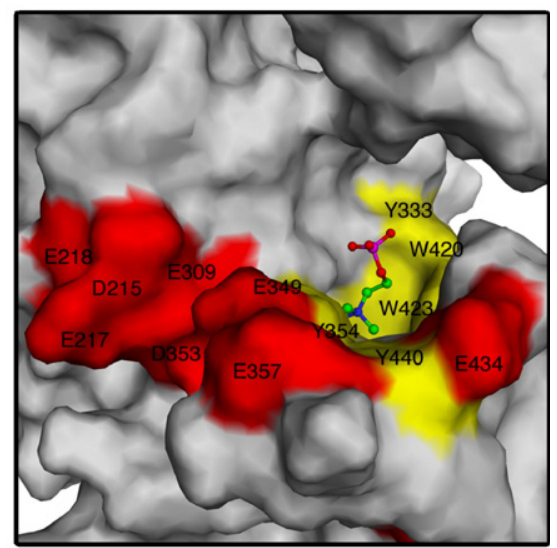

(c)
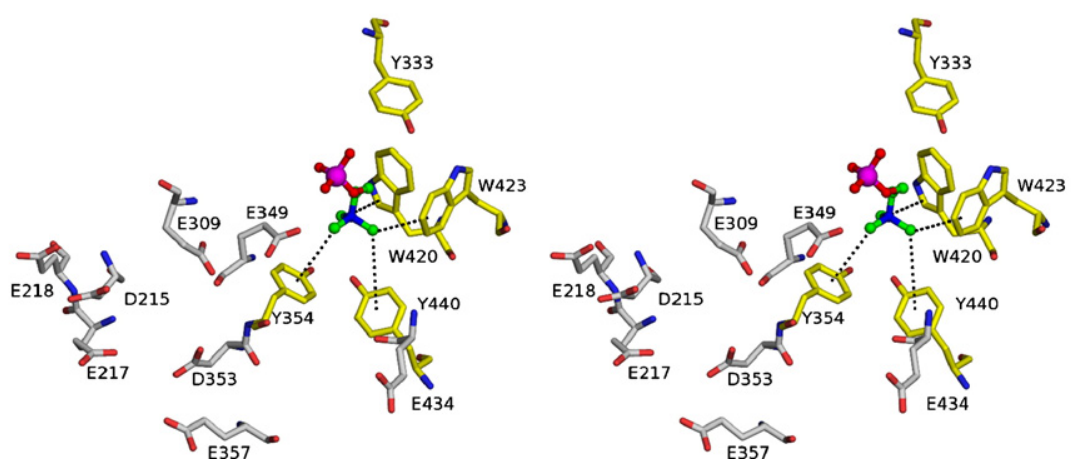

Figure 5. Choline-binding site architecture. (a) Surface representation of $\mathrm{hCK}_{\mathrm{PChol}}$ (same orientation as in Figure 1(b)) colored on the basis of the electrostatic potential of the molecule (ranging from -15 , red, to $+15 \mathrm{kT} / \mathrm{e}$, blue) calculated by APBS, ${ }^{46}$ as implemented in Pymol. (b) Zoom of the choline-binding groove, where hydrophobic and negative residues are shown as yellow and red surface, respectively. (c) Stereo view of the interactions between the quaternary ammonium moiety of choline and hydrophobic conserved residues (yellow sticks). Solvent-accessible negatively charged residues are shown in gray sticks. Oxygen, nitrogen and phosphorous atoms are red, blue and magenta, respectively.

\section{Functional residues}

The reaction catalyzed by choline kinase is the phosphorylation of choline by ATP in the presence of $\mathrm{Mg}^{2+}$, yielding phosphocholine and ADP. The clarification of the mechanism of phosphoryl transfer would represent an important advancement for developing better inhibitors of choline kinase. The presence of five structurally and functionally conserved residues among CKs, APHs and ePKs (Ser121, Arg146, Asp306, Asn311 and Asp330), together with the recently published mutagenesis studies on choline kinase from C. elegans, ${ }^{24}$ permit us to introduce with reasonable precision a model of the ternary enzyme-ADP.PChol complex (Figure 7(a) and (b)). In addition, our model includes two magnesium ions: one that bridges the $\alpha$ and $\beta$-phosphates of ADP, and a second that bridges the $\beta$-phosphate of ADP and the phosphate of PChol. Support for a model containing two magnesium ions comes from comparison of our structures with the homologous structures of $\mathrm{APH}$ $\left(3^{\prime}\right)$-IIIa (PDB id 1J7U) ${ }^{23}$ and cAPK (PDB id 1ATP), where two metals are observed, and from the presence of essential residues in $h C K \alpha 2$ that are

Figure 4. Choline-binding site interactions. (a) Stereo view representation of the choline-binding site. $2 F_{\mathrm{o}}-F_{\mathrm{c}}$ simulated annealing omit map (red) and sigma-a weighted $2 F_{0}-F_{c}$ map (blue) both contoured at $1 \sigma$ are shown surrounding PChol. Coloring scheme as in Figure 3, plus water molecules depicted as cyan spheres. (b) Ligplot ${ }^{45}$ drawing showing the interactions of PChol with $\mathrm{hCK} \alpha 2$. Ligand-bonds are colored green. Broken lines, radiating spheres and atom colors are as in Figure 3(a). Water molecules are shown as cyan spheres. 
(a)
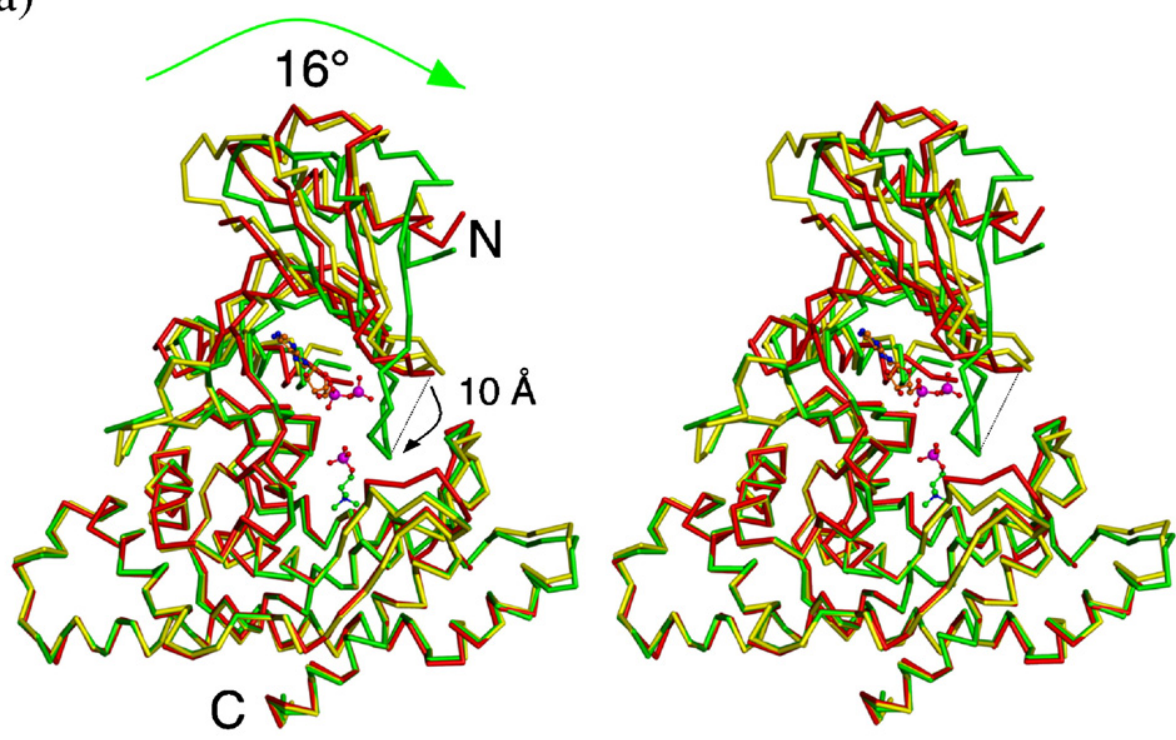

(b)

(c)
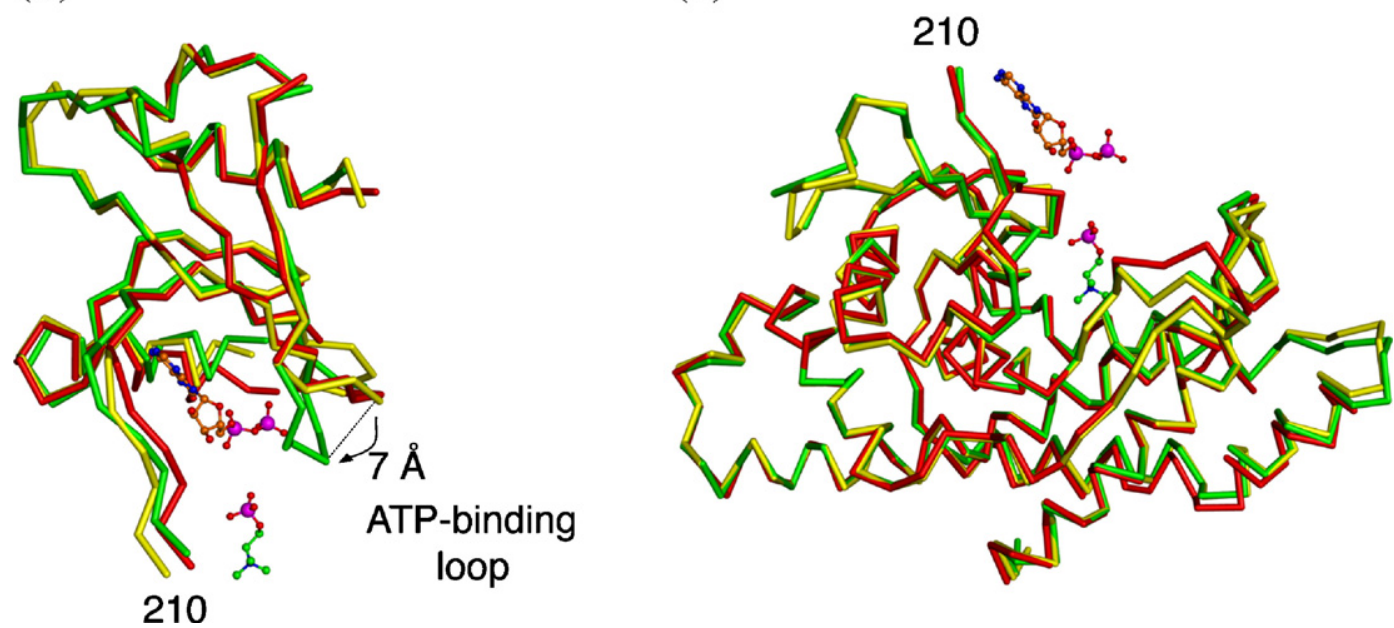

Figure 6. Conformational change in $\mathrm{hCK} \alpha 2$ upon substrate binding. Overlay of the two product-complex structures on $\mathrm{hCK}_{\mathrm{Apo}}$. $\mathrm{hCK}_{\mathrm{Apo}}, \mathrm{hCK}_{\mathrm{ADP}}$ and $\mathrm{hCK} \mathrm{K}_{\mathrm{PChol}}$ are shown as yellow, red and green $\mathrm{C}^{\alpha}$-trace, respectively. (a) Stereo view showing the overlay of the complete monomers from the three structures. The superposition matrix was calculated using residues only from the $\mathrm{C}$-terminal domain (as in (c)). The green arrow shows the movement of the $\mathrm{N}$-terminal with respect to the C-terminal domain. (b) Overlay of the N-terminal domain. The rmsd values between $\mathrm{hCK}_{\mathrm{Apo}}$ and hCK $\mathrm{ADP}_{\mathrm{Are}}$ $0.44 \AA$ for 84 atoms, and between the $\mathrm{hCK}_{\mathrm{Apo}}$ and $\mathrm{hCK} \mathrm{K}_{\mathrm{PChol}}$ are $0.77 \AA$ for 94 atoms. (c) Overlay of the C-terminal domains. The rmsd values between $\mathrm{hCK}_{\mathrm{Apo}}$ and $\mathrm{hCK}_{\mathrm{ADP}}$ are $0.5 \AA$ for 228 atoms, and $0.27 \AA$ between $\mathrm{hCK}_{\mathrm{Apo}}$ and hCK $\mathrm{PChol}_{\mathrm{l}}$ for 244 atoms.

optimally placed for the ligation of these magnesium ions in the $\mathrm{hCK} \alpha 2$ active site.

In the modeled active site, Ser121 supplies one of the six ligands to the magnesium ion that bridges the two substrates. In P-loop containing proteins, a serine or threonine residue participates directly in magnesium coordination. It seems that in $\mathrm{hCK} \alpha 2$ the participation of such a serine residue is maintained despite the lack of a P-loop. This important role for this amino acid is consistent with mutagenesis data. Mutation of Ser121 to Ala in CKA-2 results in a pronounced decrease in catalytic efficiency for both ATP (9\% of wild-type) and choline (2.7\% of wild-type). ${ }^{24}$ However, the Ser to Thr mutant has almost the same efficiency as wild- type, supporting the importance of an-OH group at this position for full activity. An alternative role for this residue would be to position the phosphocholine. In such a case, an additional water molecule is required to complete the octahedral magnesium coordination.

In addition to the above serine residue, our model calls for the aspartic acid residues at positions 306 and 330 to participate in coordinating the magnesium ion bridging the ADP and PChol molecules. Several studies demonstrate the critical importance of Asp306 in catalysis. When this Asp is mutated to Ala or Asn, CKA-2 shows total loss of activity, while when changed to Glu it retains $0.1 \%$ of the wild-type rate. ${ }^{24}$ Our structural analysis suggests that Asp306 
(a)

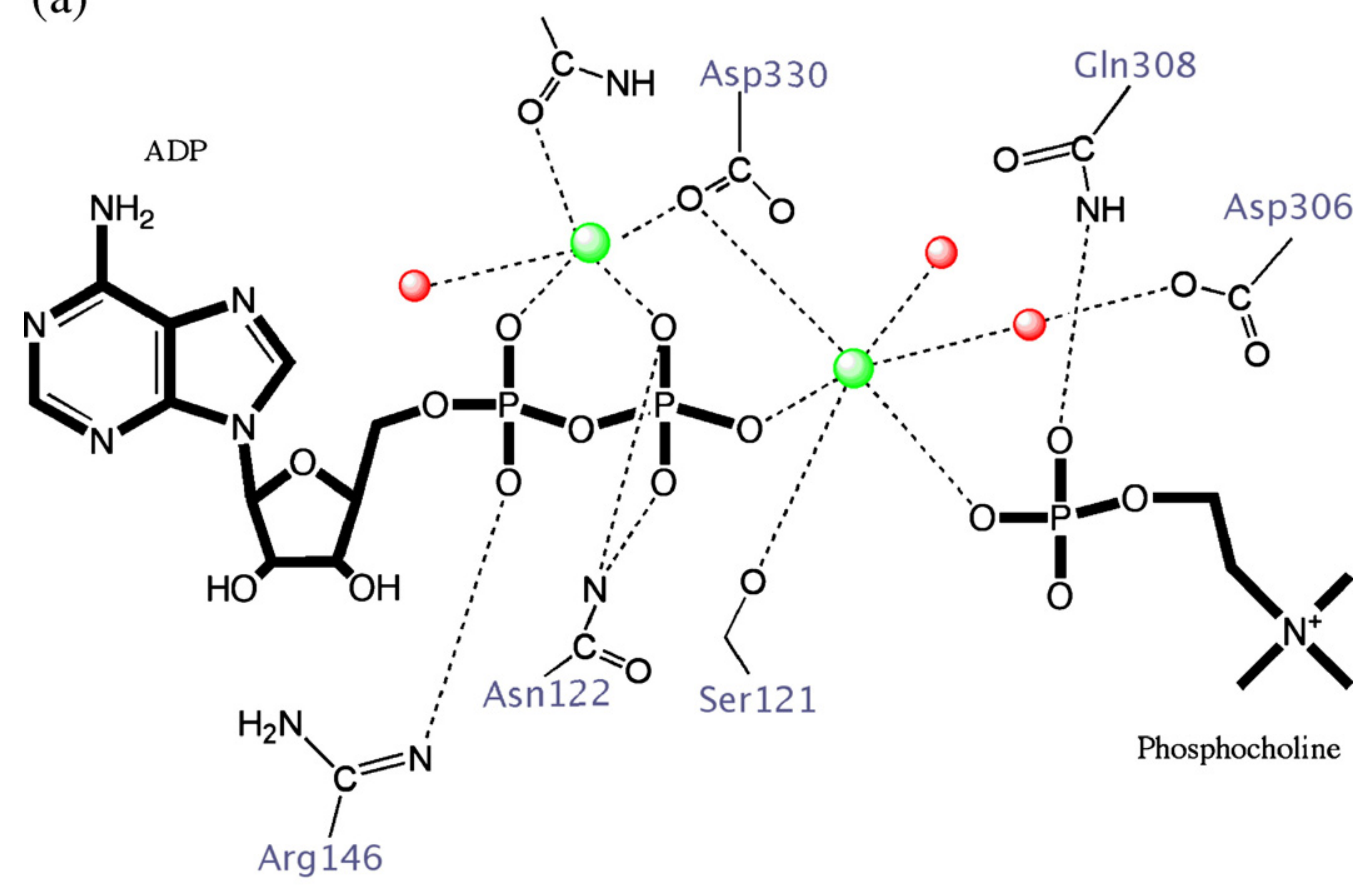

(b)

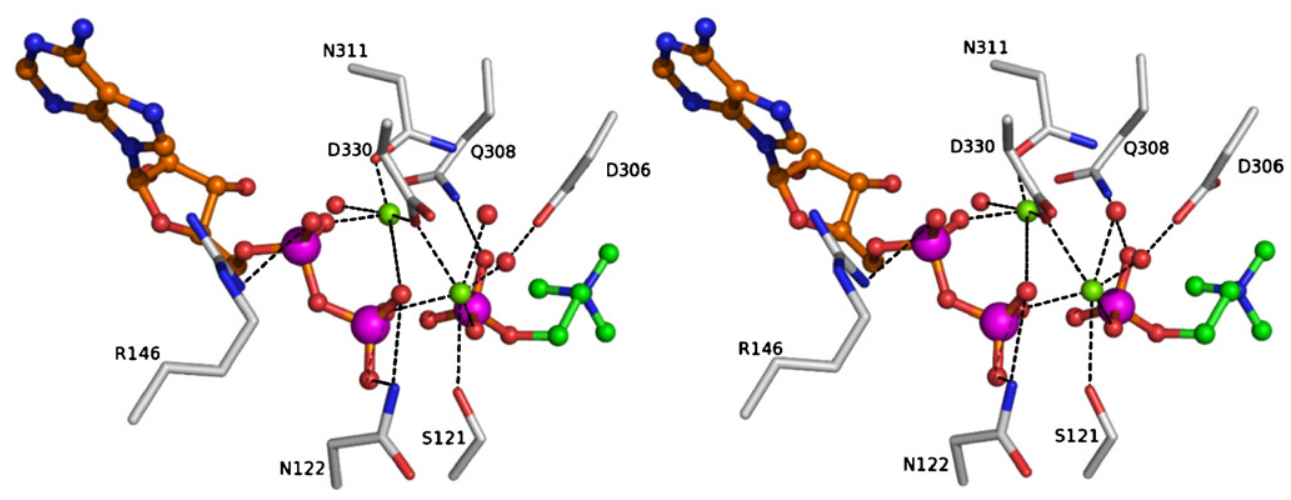

Figure 7. Model of the ternary ADP-PChol complex. (a) Scheme showing H-bond interactions between hCK $\alpha 2$ residues and ADP or phosphocholine, as well as coordination of two $\mathrm{Mg}^{2+}$, as black broken lines. (b) Stereo representation of the modeled ADP-PChol complex. This model was generated based on the closed $\mathrm{hCK}_{\mathrm{PChol}}$ structure, and analogy to $\mathrm{APH}\left(3^{\prime}\right)-\mathrm{III} a$ and cAPK. See the text for details.

plays the essential role of positioning a water molecule that ligates to a magnesium ion. Such an interpretation is consistent with structural data on $\mathrm{APH}\left(3^{\prime}\right)$-IIIa and cAPK where the corresponding residues, Asp190 and Asp166, respectively, were observed to be within H-bonding distance to a water molecule involved in magnesium ligation. While Asp306 interacts with the magnesium ion via a water molecule, Asp330 does so directly. Mutation to Ala, Asn or Glu of this residue results in lack of any detectable enzymatic activity in CKA-2, ${ }^{24}$ supporting a critical role for this residue. In fact, in our model Asp330 directly interacts with both magnesium atoms. A similar role was observed for the homologs aspartic acid in $\mathrm{APH}\left(3^{\prime}\right)$-IIIa (Asp208) and CAPK (Asp184).

In addition to the magnesium atom bridging the products, our modeling studies suggest the presence of a second magnesium ion that coordinates Asn311 and ADP. Mutagenesis of Asn311 to Ala in CKA-2 shows a severely impaired enzyme, with a $k_{\text {cat }}$ only $0.3 \%$ of wild-type, a 36 -fold increase in apparent $K_{\mathrm{m}}$ for $\mathrm{Mg}^{2+}$, and a slight increase in $K_{\mathrm{m}}$ for ATP. In our model Asn311 interacts via its side-chain oxygen with the metal ion. The corresponding magnesiumligating residue in $\mathrm{APH}\left(3^{\prime}\right)$-IIIa is Asn195, and in cAPK it is Asn171.

Asparagine 122 and glutamine 308 are residues conserved just in the CK family, and this could suggest a distinctive function with respect to APHs and ePKs. In our model the side-chain of Asn122 maintains its interaction, as seen in the $\mathrm{hCK}_{\mathrm{ADP}}$ structure, with the $\beta$-phosphate of ADP. Similarly, Gln308 preserves its interaction with the phosphate group of PChol. Thus, these residues act to correctly position the substrates for phosphoryl transfer. 
In analogy with the invariant Lys residues of $\mathrm{APH}$ (3')-IIIa (Lys44) and cAPK (Lys72) which directly participate in nucleotide binding, ${ }^{24}$ Arg146 (in $\mathrm{hCK} \alpha 2$ ) projects toward the ATP binding site and makes interaction with the nucleotide $\alpha$-oxygen atom. Mutation of this Arg residue to Ala has a significant effect on the $K_{\mathrm{m}}$ for ATP, but not on the $k_{\text {cat }}{ }^{24}$ consistent with mutagenesis data on Lys44 of APH( $\left(3^{\prime}\right)-$ IIIa. ${ }^{23}$ These observations suggest an analogous important contribution of Arg146 in substrate binding and positioning.

In summary, here we report the crystal structures of human choline kinase $\alpha 2$ in the apo form and in complex with the products ADP or phosphocholine. While no significant conformational changes are observed upon ADP binding, PChol induces a significant rotation of the N-terminal domain relative to the C-terminal domain, in addition to triggering a closing of the ATP binding loop. Modeling the simultaneous presence of ADP and phosphocholine in the closed conformation of the enzyme exposes the active site residues involved in substrate recognition, magnesium ions coordination, and catalysis. Unfortunately, despite extensive efforts we were unable to obtain crystals of $\mathrm{hCK} \alpha 2$ in the presence of the inhibitor hemicholinium. It would be interesting to determine which conformation of the enzyme is recognized by the current choline kinase inhibitors that are being tested as antiproliferative agents. Also, as these inhibitors contain several aromatic rings and possess a positive charge due to a quaternary nitrogen, it would be important to ascertain if the binding of these inhibitors exploit the choline-binding site, which is composed of several conserved hydrophobic residues. A deeper understanding of both the structure and the mechanisms regulating the activity of human $\mathrm{CK}$ at the molecular level will pave the way to the identification of novel compounds that selectively interfere with this enzyme to suppress elevated levels of choline-derived phospholipids in cancer cells.

\section{Materials and Methods}

\section{Materials}

All chemicals were reagent or molecular biology grade. Platinum $P f x$ polymerase was from Invitrogen. dNTPs were from Promega. Restriction endonucleases and DNA size markers were from New England Biolabs. Agarose gel purification, PCR product clean-up and plasmid mini prep columns were all products of Qiagen. Human liver cDNA library was a product of ResGen (Invitrogen). All oligonucleotides were supplied by IBA GmbH, Göttingen, Germany. Choline and pyruvate kinase were from Sigma. T4 DNA ligase, ATP, NADH, phosphoenolpyruvate and lactate dehydrogenase were purchased from Roche.

\section{DNA amplification by PCR}

Standard PCR reaction mixture consisted of $P f x$ amplification buffer, $0.3 \mathrm{mM}$ of each dNTP, $1.5 \mathrm{mM}$
$\mathrm{MgSO}_{4}, 1.0 \mu \mathrm{M}$ of each primer, DNA template (200 ng for cDNA library and $10 \mathrm{ng}$ for plasmid) and 1.25 unit of Platinum Pfx DNA polymerase in a total volume of $50 \mu \mathrm{l}$. Standard thermal cycling protocol was based on threestep cycling procedures with initial denaturation of the template for $10 \mathrm{~min}$ at $94{ }^{\circ} \mathrm{C}$, followed by 30 cycles of denaturation at $94{ }^{\circ} \mathrm{C}$ for $1 \mathrm{~min}$, primer annealing at $50{ }^{\circ} \mathrm{C}$ for $1 \mathrm{~min}$ and primer extension at $68^{\circ} \mathrm{C}$ for another $2 \mathrm{~min}$. A final extension step at $68^{\circ} \mathrm{C}$ for 5 min was introduced after the cycling reactions.

\section{Cloning of full length and $\Delta 49 \mathrm{~N}-\mathrm{hCKa2}$}

Based on the sequence information of hCK $\alpha 2$ previously reported by Hosaka et al., ${ }^{32}$ the cDNA sequence of hCK $\alpha 2$ was PCR amplified from human liver cDNA library in two overlapping fragments. The first fragment was generated by using the sense primer $5^{\prime}$-GGGAATTCCATATGAAAACCAAATTCTGCACCG-3' (CM14) and antisense primer 5'-CTTGTTCAGAGCCCTCTTTATTAC$3^{\prime}$ (CM17). The second fragment was amplified by sense primer 5'-GTAATAAAGAGGGCTCTGAACAAG-3' (CM16) and antisense primer 5'-CGCGGATCCTCACACCCCAAGCTTCCTC-3' (CM15). CM14 and CM15 carry NdeI and BamHI cloning sites, respectively. CM16 and CM17 are mutagenesis primers for deletion of the internal BamHI site. Both fragments were subsequently joined by PCR using primers CM14 and CM15. The resulting PCR product with the size corresponding to the full-length $\mathrm{hCK} \alpha 2$ was treated with the restriction enzymes NdeI and BamHI and ligated into the pGEXRB vector ${ }^{33}$ to create pGEX-RB-hCK $\alpha 2$.

$\Delta 49 \mathrm{~N}-\mathrm{hCK} \alpha 2$ was generated from pGEX-RB-hCK $\alpha 2$ using the sense primer 5'-GGGAATTCCATATGGGCCAACAGCCGCCGCTCGCGCTGC-3' (WC62) and CM15 as antisense primer. The resulting PCR product was digested with NdeI and BamH1 and ligated into pGEX-RB to give pGEX-RB- $\Delta 49 \mathrm{~N}-\mathrm{hCK} \alpha 2$. In all cases, clone integrity was confirmed by sequencing. The rationale behind this deletion construct was to generate a construct that starts with the first residue observed in the structure of choline kinase A-2 from C. elegans, ${ }^{20}$ and in this way obtain a protein that is more amenable to structural studies, but yet maintains its full catalytic function.

\section{Protein expression and purification}

Recombinant glutathione-S-transferase (GST)-tagged $\Delta 49 \mathrm{~N}-\mathrm{hCK} \alpha 2$ was produced in Escherichia coli strain BL21(DE3) containing the vector pGEX-RB- $\Delta 49 \mathrm{~N}$ hCK $\alpha 2$. After induction with $1 \mathrm{mM}$ IPTG for $18 \mathrm{~h}$ at $25{ }^{\circ} \mathrm{C}$, the soluble fraction of the cell lysate was loaded onto a glutathione-Sepharose column (Amersham). The purification included proteolytic cleavage of the GST tag with thrombin, anionic exchange chromatography via ResourceQ, and size-exclusion via Superdex-200 column (Amersham). The protein eluted at a volume consistent with a dimeric molecule. The full-length protein was purified using a similar protocol.

\section{Enzyme assay}

Choline kinase activity was assayed spectrophotometrically using a modified pyruvate kinase/lactate dehydrogenase-coupled system. ${ }^{34}$ The reaction contained $100 \mathrm{mM}$ Tris- $\mathrm{HCl}$ buffer (pH 7.5), $100 \mathrm{mM} \mathrm{KCl}, 10 \mathrm{mM}$ 
$\mathrm{MgCl}_{2}, 0.5 \mathrm{mM}$ phosphoenolpyruvate, $0.25 \mathrm{mM} \mathrm{NADH}$ four units of pyruvate kinase, five units of lactate dehydrogenase, purified enzyme, and substrates in a total volume of $1 \mathrm{ml}$. For determination of steady-state kinetic parameters the concentration of one substrate was kept constant at $2 \mathrm{mM}$ ATP or $4 \mathrm{mM}$ choline while the concentration of the other was varied. The reaction performed at $37{ }^{\circ} \mathrm{C}$ was initiated by the addition of choline. ADP formation was followed spectrophotometrically using a UVIKON 943 (Kontron) spectrophotometer by measuring the decrease of NADH at $340 \mathrm{~nm}$.

\section{Crystallization and data collection}

Crystals of $\mathrm{hCK}_{\mathrm{Apo}}$, diffracting to $2.1 \AA$ A resolution, were grown by the sitting-drop vapor diffusion method. Platelike crystals grew at $293 \mathrm{~K}$ to a maximum size of $20 \mu \mathrm{m} \times 100 \mu \mathrm{m} \times 500 \mu \mathrm{m}$ from drops containing $1.5 \mu 1$ of $11 \mathrm{mg} / \mathrm{ml} \Delta 49-\mathrm{hCK} \alpha 2$ in crystallization buffer $(25 \mathrm{mM}$ Tris- $\mathrm{HCl}$ (pH 7.5), $25 \mathrm{mM} \mathrm{KCl}, 0.5 \mathrm{mM}$ dithiothreitol), $0.5 \mu \mathrm{l}$ of $0.1 \mathrm{M} \mathrm{MgCl}_{2}$ and $3 \mu \mathrm{l}$ of well solution (12-20\% (w/v)PEG 3350, 0.2 M NaF). Crystals of the hCK $\mathrm{ADP}_{\mathrm{ADP}}$ and

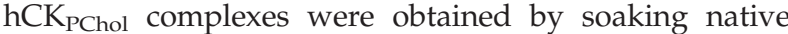
crystals for $30 \mathrm{~min}$ in solutions consisting of $20 \%$ PEG 3350, $0.2 \mathrm{M} \mathrm{NaF}$, plus $10 \mathrm{mM}$ ADP and $20 \mathrm{mM}$ phosphocholine, respectively. $\mathrm{hCK}_{\mathrm{ADP}}$ and $\mathrm{hCK}_{\mathrm{PChol}}$ crystals diffracted to 3.1 and $2.4 \AA$ resolution, respectively. All crystals belong to space group $P 2_{1} 2_{1} 2_{1}$, but whereas the unit cell dimensions along the $a$ and $b$ axes were only moderately changed by the soaking procedure, the $c$-axis exhibited considerable lengthening: from $132.1 \AA$ in the apo-crystals to $158.7 \AA$ in the ADP complex, and to $172.2 \AA$ in the phosphocholine complex (see Table 2). Before data collection, crystals were washed in a cryoprotectant solution of 30\% PEG 3350, $0.2 \mathrm{M} \mathrm{NaF}$ and ligand (when required) and then flash-cooled in a $100 \mathrm{~K}$ nitrogen stream. Diffraction data on native crystals were collected at the Cornell High Energy Synchrotron Source (CHESS) beamline A1, using an ADSC Quantum-210 CCD detector. Data collections on product-bound crystals were carried out at APS-SerCAT (Argonne National Lab) beamline ID-22, using an Mar-300 CCD detector. All the diffraction data were processed using $\mathrm{XDS}^{35}$ and were scaled and reduced with programs of the CCP4 package. ${ }^{36}$ The mechanical fragility of the crystals required extensive screenings to identify a crystal with a suitable diffraction pattern. However, some crystals splitting could not be avoided and may explain the relatively high $R_{\text {sym }}$ values. Data collection statistics are summarized in Table 2.

\section{Crystallographic structure solution and refinement}

The structure of $\mathrm{hCK}_{\mathrm{Apo}}$ was solved by molecular replacement in PHASER ${ }^{37}$ with search model based on coordinates of $C$. elegans choline kinase A-2 (CKA-2, PDB id 1NW1). ${ }^{20}$ The final model was refined using $\mathrm{CNS}^{38}$ and REFMAC $^{39}$ with a final $R$-factor of $19.8 \%\left(R_{\text {free }} 25.6 \%\right)$. Coordinates of the refined $\mathrm{hCK}_{\mathrm{Apo}}$ were used as search model to solve the structures of the $\mathrm{hCK}_{\mathrm{ADP}}$ and $\mathrm{hCK}_{\mathrm{PChol}}$ complexes, using the molecular replacement methods as implemented in MOLREP. ${ }^{40}$ Top solutions from the translation search were then subjected to rigid-body refinement, followed by steps of manual rebuilding carried out with $\mathrm{O}^{41}$ and $\mathrm{COOT}^{42}$ and restrained refinement with REFMAC. ${ }^{39}$ After each round of refinement, $\sigma A$-weighted $2 F_{\mathrm{o}}-F_{\mathrm{c}}$ and $F_{\mathrm{o}}-F_{\mathrm{c}}$ difference electron density maps were calculated and inspected. The presence of clear extra electron density was therefore observed for ADP and PChol, respectively. Atomic coordinates of the complexes were refined using the same protocol employed for the native structure, with a final $R$-factor of $26.3 \%\left(R_{\text {free }} 32.8 \%\right)$ for $\mathrm{hCK}_{\mathrm{ADP}}$, and a final $R$-factor of $21.4 \%\left(R_{\text {free }} 25.8 \%\right)$ for $\mathrm{hCK}_{\mathrm{PChol}}$. The same set of Miller indices (5\% of the total) were set aside for free R-factor calculations during refinement of native and ligated structures. ${ }^{43}$ Note that a lack of traceable electron density in some regions of the $\mathrm{hCK}_{\mathrm{ADP}}$ structure prevented us from modelling $\sim 25 \%$ of the residues in comparison to the apo-structure. Specifically, residues 131-139, 149-175 (missing insertion in all pdbs), 262-268, 314-326 in chain A; 87-91, 118-121, 131141, 148-176, 256-277, 317-323, 388-389, 424-440 in chain B. Refinement statistics are summarised in Table 2.

Model analysis was carried out using Procheck. ${ }^{44}$ Figures were generated with Ligplot ${ }^{45}$ and Pymol.\$

\section{Modeling of the ADP-phosphocholine complex}

Examinations of our structures, the open $\mathrm{hCK}_{\mathrm{ADP}}$ and the closed $\mathrm{hCK}_{\mathrm{PChol}}$, suggest that the enzyme conformation observed in the latter better describes the presence of both substrates. To position ADP in the $\mathrm{hCK}_{\mathrm{PChol}}$ structure, we first applied a transformation matrix to the ADP molecule, which was calculated from the change in conformation of residues 202-210 between the hCK $\mathrm{ADP}$ and $\mathrm{hCK}_{\mathrm{PChol}}$ structures. These residues interact with the adenine moiety of ADP. In addition, we optimized the ADP position in our model by comparison with the homologous structures of $\mathrm{APH}\left(3^{\prime}\right)$-IIIa and cAPK.

\section{Protein Data Bank accession codes}

Coordinates and structure factors have been deposited in the RCSB Protein Data Bank with accession codes 2CKO $\left(\mathrm{hCK}_{\mathrm{Apo}}\right), 2 \mathrm{CKP}\left(\mathrm{hCK}_{\mathrm{ADP}}\right)$, and $2 \mathrm{CKQ}\left(\mathrm{hCK}_{\mathrm{PChol}}\right)$.

\section{Acknowledgements}

This work was supported by NIH grant DK061397 to E.M. and A.L., M.K. by the Max Planck Gesellschaft, and W.C.S.T. by fellowship under the Academic Staff Training Scheme, Universiti Sains Malaysia. We thank the staff at SERCAT and CHESS for their assistance in data collection.

\section{References}

1. Kent, C. (1990). Regulation of phosphatidylcholine biosynthesis. Progr. Lipid Res. 29, 87-105.

2. Exton, J. H. (1994). Phosphatidylcholine breakdown and signal transduction. Biochim. Biophys. Acta, 1212, 26-42.

3. Ishidate, K. (1997). Choline/ethanolamine kinase from mammalian tissues. Biochim. Biophys. Acta, 1348, 70-78.

4. Kent, C. \& Carman, G. M. (1999). Interactions among pathways for phosphatidylcholine metabolism, CTP synthesis and secretion through the Golgi apparatus. Trends Biochem. Sci. 24, 146-150.

\$ttp://www.pymol.org 
5. Litvak, V., Dahan, N., Ramachandran, S., Sabanay, H \& Lev, S. (2005). Maintenance of the diacylglycerol level in the Golgi apparatus by the Nir2 protein is critical for Golgi secretory function. Nature Cell Biol. 7, 225-234.

6. Cui, Z. \& Houweling, M. (2002). Phosphatidylcholine and cell death. Biochim. Biophys. Acta, 1585, 87-96.

7. Ramírez De Molina, A., Rodríguez-González, A. Gutiérrez, R., Martínez-Piñeiro, L., Sánchez, J. J., Bonilla, F. et al. (2002). Overexpression of choline kinase is a frequent feature in human tumor-derived cell lines and in lung, prostate, and colorectal human cancers. Biochem. Biophys. Res. Commun. 296, 580-583.

8. Ramírez De Molina, A., Penalva, V., Lucas, L. \& Lacal J. C. (2002). Regulation of choline kinase activity by Ras proteins involves Ral-GDS and PI3K. Oncogene, 21, 937-946.

9. Ramírez De Molina, A., Gutierrez, R. \& Ramos, M. A. (2002). Increased choline kinase activity in human breast carcinomas: clinical evidence for a potential novel antitumor strategy. Oncogene, 21, 4317-4322.

10. Ruiz-Cabello, J. \& Cohen, J. S. (1992). Phospholipid metabolites as indicators of cancer cell function. NMR Biomed. 5, 226-233.

11. de Certaines, J. D., Larsenm, V. A., Podo, F., Carpinelli, G., Briot, O. \& Henriksen, O. (1994). In vivo 31P MRS of experimental tumours. NMR Biomed. 6, 345-365.

12. Ramírez de Molina, A., Gallego-Ortiga, D., Sarmentero, J., Bañez-Coronel, M., Martin-Cantalejo, Y. \& Lacal, J. C. (2005). Choline kinase is a novel oncogene that potentiates Rho-A-induced carcinogenesis. Cancer Res. 65, 5647-5653.

13. Hernández-Alcoceba, R., Fernandez, F. \& Lacal, J. C. (1997). Choline kinase inhibitors as a novel approach for antiproliferative drug design. Oncogene, 15, 2289-2301.

14. Rodríguez-González, A., Ramírez de Molina, A., Benítez-Rajal, J. \& Lacal, J. C. (2003). Phospholipase $\mathrm{D}$ and choline kinase: their role in cancer develoment and their potential as drug targets. Progr. Cell Cycle Res. 5, 191-201.

15. Rodríguez-González, A., Ramírez de Molina, A., Fernández, F. \& Lacal, J. C. (2004). Choline kinase inhibition induces the increase in ceramides resulting in a highly specific and selective cytotoxic antitumoral strategy as a potential mechanism of action. Oncogene, 23, 8247-8259.

16. Rodríguez-González, A., Ramírez de Molina, A. Bañez-Coronel, M., Megias, D. \& Lacal, J. C. (2005) Inhibition of choline kinase renders a highly selective cytotoxic effect in tumour cells through a mitocondrial independent mechanism. Int. J. Oncol. 26, 999-1008.

17. Al-Saffar, N. M., Troy, H., de Molina, A. R., Jackson, L. E., Madhu, B., Griffiths, J. R. et al. (2006). Noninvasive magnetic resonance spectroscopic pharmacodynamic markers of the choline kinase inhibitor MN58b in human carcinoma models. Cancer Res. 66, 427-434.

18. Hernandez-Alcoceba, R., Fernandez, F. \& Lacal, J. C. (1999). In vivo antitumor activity of choline kinase inhibitors: a novel target for anticancer drug discovery. Cancer Res. 59, 3112-3118.

19. Aoyama, C., Huanan, L. \& Kozo, I. (2004). Structure and function of choline kinase isoforms in mammalian cells. Progr. Lipid Res. 43, 266-281.

20. Peisach, D., Patricia, G., Kent, C. \& Zhaohui, X. (2003). The crystal structure of choline kinase reveals a eukaryotic protein kinase fold. Structure, 11, 703-713.

21. Scheeff, E. D. \& Bourne, P. E. (2005). Structural evolution of the protein kinase-like superfamily. Plos Comp. Biol. 1, 359-381.

22. Brenner, S. (1987). Phosphotransferase sequence homology. Nature, 329, 21.

23. Hon, W. C., McKay, G. A., Thompson, P. R., Sweet, R. M., Yang, D. S. C., Wright, G. D. \& Berghuis, A. M. (1997). Structure of an enzyme required for aminoglycoside antibiotic resistance reveals homology to eukaryotic protein kinases. Cell, 89, 887-895.

24. Yuan, C. \& Kent, C. (2004). Identification of critical residues of choline kinase A2 from Caenorhabditis elegans. J. Biol. Chem. 279, 17801-17809.

25. Kinoshita, K., Sadanami, K., Kidera, A. \& Go, N. (1999). Structural motif of phosphate-binding site common to various protein superfamilies: allagainst-all structural comparison of protein-mononuncleotide complexes. Protein Eng. 12, 11-14.

26. Zheng, J., Knighton, D. R., ten Eyck, L. F., Karlson, R., Xuong, N., Taylor, S. S. \& Sowadski, J. M. (1993). Crystal structure of the catalytic subunit of cAMPdependent protein kinase complexed with MgATP and peptide inhibitor. Biochemistry, 32, 2154-2161.

27. Hutter, M. C. \& Helms, V. (1999). Influence of key residues on the reaction mechanism of the cAMPdependent protein kinase. Protein Sci. 8, 2728-2733.

28. Liao, H., Aoyama, C., Ishidate, K. \& Teraoka, H. (2006). Deletion and alanine mutation analyses for the formation of active homo- or hetero-dimer complexes of mouse choline kinase- $\alpha$ and $-\beta$. Biochim. Biophys. Acta, 1761, 111-120.

29. Brown, M., Schumacher, M. A., Wiens, G. D., Brennan, R. G. \& Rittenberg, M. B. (2000). The strucutral basis of repertoire shift in an immune response to phosphocholine. J. Exp. Med. 191, 2101-2112.

30. Wade, R. C., Gabdoulline, R. R., Lüdemann, S. K. \& Lounnas, V. (1998). Electrostatic steering and ionic tethering in enzyme-ligand binding: insights from simulations. Proc. Natl Acad. Sci. USA, 95, 5942-5949.

31. Hayward, S. \& Lee, R. A. (2002). Improvements in the analysis of domain motions in proteins from conformational change: DynDom version 1.50. J. Mol. Graph. Model. 3, 181-183.

32. Hosaka, K., Tanaka, S., Nikawa, J. \& Yamashita, S. (1992). Cloning of a human choline kinase cDNA by complementation of the yeast cki mutation. FEBS Letters, 304, 229-232.

33. Brundiers, R., Lavie, A., Veit, T., Reinstein, J., Schlichting, I., Ostermann, N. et al. (1999). Modifying human thymidylate kinase to potentiate azidothymidine activation. J. Biol. Chem. 274, 35289-35292.

34. Uchida, T. \& Yamashita, S. (1992). Choline/ethanolamine kinase from rat brain. Methods Enzymol. 209, 147-153.

35. Kabsch, W. (1993). Automatic processing of rotation diffraction data from crystals of initially unknown symmetry and cell constants. J. Appl. Crystallog. 26, 795-800.

36. CCP4. (1994). The CCP4 Suite: programs for protein crystallography. Acta Crystallog. sect. D, 50, 760-767.

37. Read, R. J. (2001). Pushing the boundaries of molecular replacement with maximum likelihood. Acta Crystallog. sect. D, 57, 1373-1382.

38. Brunger, A. T., Adams, P. D., Clore, G. M., DeLano, W. L., Gros, P., Grosse-Kunstleve, R. W. et al. (1998). Crystallography and NMR system: a new software suite for macromolecular structure determination. Acta Crystallog. sect. D, 54, 905-921.

39. Murshudov, G. N., Vagin, A. A. \& Dodson, E. J. (1997). Refinement of macromolecular structures by the 
maximum-likelihood method. Acta Crystallog. sect. D, 53, 240-255.

40. Vagin, A. \& Teplyakov, A. (1997). MOLREP: an automated program for molecular replacement. J. Appl. Crystallog. 30, 1022-1025.

41. Jones, T. A., Zou, J. Y., Cowan, S. W. \& Kieldgaard, M. (1991). Improved methods for building protein models in electron density maps and the location of errors in these models. Acta Crystallog. sect. A, 47, 110-119.

42. Emsley, P. \& Cowtan, K. (2004). Coot: model-building tools for molecular graphics. Acta Crystallog. sect. D, 60, 2126-2132.

43. Brunger, A. T. (1992). The free R value. A novel statistical quantity for assessing the accuracy of crystal structures. Nature, 355, 472-475.

44. Laskowski, R. A., MacArthur, M. W., Moss, D. S. \& Thornton, J. M. (1993). PROCHECK: a program to check the stereochemistry quality of protein structures. J. Appl. Crystallog. 26, 283-291.

45. Wallace, A. C., Laskowski, R. A. \& Thornton, J. M. (1995). LIGPLOT: a program to generate schematic diagrams of protein-ligand interactions. Protein Eng. 8, 127-134.

46. Baker, N. A., Sept, D., Joseph, S., Holst, M. J. \& McCammon, J. A. (2001). Electrostatics of nanosystems: application to microtubules and the ribosome. Proc. Natl Acad. Sci. USA, 98, 10037-10041.

Edited by M. Guss

(Received 17 July 2006; received in revised form 25 August 2006; accepted 28 August 2006) Available online 3 September 2006 